\title{
Olfactory Ensheathing Cell Transplantation after a Complete Spinal Cord Transection Mediates Neuroprotective and Immunomodulatory Mechanisms to Facilitate Regeneration
}

\author{
Rana R. Khankan, ${ }^{1}$ Khris G. Griffis, ${ }^{1}$ James R. Haggerty-Skeans, ${ }^{1}$ Hui Zhong, ${ }^{2}$ Roland R. Roy, ${ }^{1,2}$ V. Reggie Edgerton, ${ }^{1,2}$ \\ and Patricia E. Phelps ${ }^{1,2}$ \\ 'Department of Integrative Biology and Physiology, and 2Brain Research Institute, University of California-Los Angeles, Los Angeles, California 90095
}

\begin{abstract}
Multiple neural and peripheral cell types rapidly respond to tissue damage after spinal cord injury to form a structurally and chemically inhibitory scar that limits axon regeneration. Astrocytes form an astroglial scar and produce chondroitin sulfate proteoglycans (CSPGs), activate microglia, and recruit blood-derived immune cells to the lesion for debris removal. One beneficial therapy, olfactory ensheathing cell (OEC) transplantation, results in functional improvements and promotes axon regeneration after spinal cord injury. The lack of an OEC-specific marker, however, has limited the investigation of mechanisms underlying their proregenerative effects. We compared the effects of enhanced green fluorescent protein-labeled fibroblast (FB) and OEC transplants acutely after a complete low-thoracic spinal cord transection in adult rats. We assessed the preservation of neurons and serotonergic axons, the levels of inhibitory CSPGs and myelin debris, and the extent of immune cell activation between 1 and 8 weeks postinjury. Our findings indicate that OECs survive longer than FBs post-transplantation, preserve axons and neurons, and reduce inhibitory molecules in the lesion core. Additionally, we show that OECs limit immune-cell activation and infiltration, whereas FBs alter astroglial scar formation and increase immune-cell infiltration and concomitant secondary tissue damage. Administration of cyclosporine-A to enhance graft survival demonstrated that immune suppression can augment OEC contact-mediated protection of axons and neurons during the first 2 weeks postinjury. Collectively, these data suggest that OECs have neuroprotective and immunomodulatory mechanisms that create a supportive environment for neuronal survival and axon regeneration after spinal cord injury.
\end{abstract}

Key words: 5-HT; chondroitin sulfate proteoglycans; inflammation; myelin; OEC; spinal cord injury

Significance Statement

Spinal cord injury creates physical and chemical barriers to axon regeneration. We used a complete spinal cord transection model and olfactory ensheathing cell (OEC) or fibroblast (FB; control) transplantation as a repair strategy. OECs, but not FBs, intermingled with astrocytes, facilitated astroglial scar border formation and sequestered invading peripheral cells. OECs attenuated immune cell infiltration, reduced secondary tissue damage, protected neurons and axons in the lesion core, and helped clear myelin debris. Immunosuppression enhanced survival of OECs and FBs, but only OEC transplantation promoted scaffold formation in the lesion site that facilitated axon regeneration and neuron preservation.

\section{Introduction}

The regenerative capacity of adult mammalian neurons after injury is reduced by astroglial scar formation, inhibitory myelin-

Received Jan. 8, 2016; revised April 28, 2016; accepted May 2, 2016.

Author contributions: R.R.K., V.R.E., and P.E.P. designed research; R.R.K., K.G.G., J.R.H.-S., H.Z., and R.R.R. performed research; R.R.K., K.G.G., and J.R.H.-S. analyzed data; R.R.K., R.R.R., V.R.E., and P.E.P. wrote the paper.

This work was supported by National Institute of Neurological Disorders and Stroke Grants 1R01NS54159 (V.R.E., P.E.P.), 1R01NS076976 (V.R.E., P.E.P.), and the National Institute of Child Health and Human Development Grant P3OHD004612 (IDDRC microscopy core). We thank Dr Ellen Carpenter for editing the paper, Dr Jeff Gornbein for assistance in the statistical analyses, Dr Greg Lawson and Maynor Herrera for aid in postsurgical care, Norianne Ingram for tracing neurites, Alyssa Capili, Danielle Perez, and Aly Mulji for assistance with animal care and preparation of data analyses, Marianne Cilluffo and Katie Ingraham for assistance with primary OEC cultures, Jamie Church associated proteins, chondroitin sulfate proteoglycan (CSPG) deposition, and inflammatory cell activation that together contribute to a nonpermissive environment and minimal functional recovery (Reier and Houle, 1988; Fitch et al., 1999; Fitch and

and Dr Dana McTigue for the 0il Red 0 protocol, Dr Stephen Runyan for preparation of isolated myelin, and Dr Michael Sofroniew for helpful advice.

The authors declare no competing financial interests.

Correspondence should be addressed to Dr Patricia E. Phelps, UCLA, Department of Integrative Biology and Physiology, Terasaki Life Sciences Building, 610 Charles Young Drive East, Los Angeles, CA 90095-7239. E-mail: pphelps@physci.ucla.edu.

DOI:10.1523/JNEUROSCI.0085-16.2016

Copyright $\odot 2016$ the authors $\quad 0270-6474 / 16 / 366269-18 \$ 15.00 / 0$ 
Silver, 2008; Buss et al., 2009; Hu et al., 2010). To facilitate axonal regeneration and subsequent synaptic connectivity, therapies must overcome these post-traumatic growth-inhibitory factors and promote tissue preservation. Examples of such therapies include the reduction of glial scar inhibition, the removal of cellular debris, and the establishment of a permissive cellular bridge across the lesion site. Additionally, treatments that provide neurotrophic factors to spared neurons and function in axonal guidance may enhance the intrinsic capacity of injured neurons to regenerate functional synaptic connections and initiate recovery.

After an olfactory nerve injury, olfactory ensheathing cells (OECs) facilitate the generation of new olfactory receptor neurons and maintain a conduit for their axons to grow along as they project to their olfactory bulb targets (Lipson et al., 2003; Li et al., 2005a). OECs express adhesion molecules involved in axonal outgrowth, secrete trophic factors, such as brain derived neurotrophic factor and ciliary neurotrophic factor (CNTF), and ensheath growing axons to protect them from inhibitory molecules. Over the past decade, many studies reported that OECs support axon regeneration even after a severe spinal cord injury in rodents and humans (Ramón-Cueto et al., 1998, 2000; Lu et al., 2002; López-Vales et al., 2006; Kubasak et al., 2008; Takeoka et al., 2011; Ziegler et al., 2011; Granger et al., 2012; Tabakow et al., 2014). Collectively these studies have generated anatomical, physiological, and behavioral evidence that OEC transplantation supports the regeneration of corticospinal tract axons, preserves neurons and axons near the lesion site, increases the recovery of motor-evoked potentials in the hindlimb muscles, and facilitates stepping and grid climbing ability compared with media-treated controls. Despite these functional improvements, the lack of an OEC-specific marker has hampered the irrefutable identification of OEC transplants in spinal cord injury studies, and thus the mechanisms by which OECs may facilitate axon regeneration and functional recovery are unclear.

To better understand how acutely transplanted OECs interact with the glial scar and surrounding inhibitory environment after a complete spinal cord transection, we used enhanced green fluorescent protein (GFP)-labeled control fibroblasts (FBs) and OECs derived from GFP-transgenic rats (Perry et al., 1999). To assess the survival and engraftment, we determined the volume of GFP-positive cells in the lesion core between 1 and 8 weeks postinjury and found that OECs survived more robustly than FBs. Next, we asked whether the presence of OECs preserved neurons and provided a permissive environment for axons postinjury. We found more neurons and axons in the lesion core and fewer inhibitory molecules in OEC- than FB-transplanted spinal cords. To determine whether FBs and OECs differed in their modification of the lesion site, we examined astroglial scar formation and quantified the density of activated immune cells and their infiltration into the spinal cord stumps. In a second part of the study, we asked whether the pharmacological immunosuppressant, cyclosporine-A (CSA), would enhance graft survival and augment the beneficial effects of OECs. CSA treatment improved both FB and OEC survival, and confirmed that OECs are neuroprotective, growth permissive cells that modulate the inhibitory environment, reduce secondary tissue damage, and promote axon regeneration.

\section{Materials and Methods}

Animals. All animal experimental procedures were approved by the Chancellor's Animal Research Committee at UCLA and conducted in accordance with the National Institutes of Health guidelines. Animals
Table 1. Number of transplanted rats with GFP-positive cells

\begin{tabular}{|c|c|c|c|c|}
\hline $\begin{array}{l}\text { Weeks } \\
\text { postinjury }\end{array}$ & Treatment & $\begin{array}{l}\text { Rats, } \\
n\end{array}$ & $\begin{array}{l}\text { Rats with } \\
\text { engrafted cells }\end{array}$ & $\begin{array}{l}\text { Location of surviving engrafted } \\
\text { cells }\end{array}$ \\
\hline \multirow[t]{2}{*}{1} & $F B$ & 4 & 4 of 4 & Stumps and lesion core \\
\hline & OEC & 5 & 5 of 5 & Stumps and lesion core \\
\hline \multirow[t]{4}{*}{2} & $F B$ & 6 & 2 of 6 & Stumps: 1 of 2; lesion core: 1 of 2 \\
\hline & $\mathrm{OEC}$ & 5 & 3 of 5 & Stumps: 2 of 3 ; lesion core: 1 of 3 \\
\hline & $F B+C S A$ & 4 & 4 of 4 & Stumps and lesion core \\
\hline & $\mathrm{OEC}+\mathrm{CSA}$ & 4 & 4 of 4 & Stumps and lesion core \\
\hline \multirow[t]{2}{*}{4} & FB & 5 & 0 of 5 & None present \\
\hline & OEC & 8 & 5 of 8 & Stumps: 2 of 5 ; lesion core: 3 of 5 \\
\hline \multirow[t]{4}{*}{8} & $F B$ & 6 & 0 of 6 & None present \\
\hline & OEC & 6 & 0 of 6 & None present \\
\hline & $\mathrm{FB}+\mathrm{CSA}$ & 3 & 2 of 3 & Stumps and lesion core \\
\hline & $\mathrm{OEC}+\mathrm{CSA}$ & 5 & 3 of 5 & Stumps: 1 of 3 ; lesion core: 2 of 3 \\
\hline
\end{tabular}

The number of transplanted rats in which GFP-positive cells were identified in the lesion core and/or spinal cord stumps postinjury. Total $\mathrm{FB}=12$; Total $\mathrm{OEC}=20$.

were housed under standard conditions with ad libitum access to food and water. We established a breeding colony of GFP-expressing SpragueDawley rats (Perry et al., 1999). Homozygous and heterozygous rats were generated and confirmed with PCR (Perry et al., 1999) and rats 8-10 weeks old were used to obtain GFP-labeled FBs and OECs. All cells transplanted into rats were GFP-labeled, and will be referred to as FB or OEC throughout the paper. Wild-type postnatal day 8 rat pups were used in cortical neurite outgrowth experiments. An overdose of ketaminexylazine was used for euthanasia before the extraction of the olfactory bulbs, cerebral hemispheres, or abdominal skin biopsies. Sixty-one female Sprague-Dawley rats (Charles River Laboratories), 10-12 weeks of age, received cell transplants directly after a complete low-thoracic spinal cord transection and were maintained for $1,2,4$, or 8 weeks postinjury (Table 1).

Olfactory bulb-derived OEC cultures. Methods to prepare all OEC primary and immunopurified cultures were similar to those of RamónCueto et al. (2000) and identical to those recently reported (Khankan et al., 2015). After OEC dissection from the first two layers of the olfactory bulb, meninges and blood vessels were removed to reduce fibroblast contamination. Cells were dissociated in $0.1 \%$ trypsin (Invitrogen) and resuspended in a mixture of 1:1 Dulbecco's Modified Eagle's/Ham's F12 medium (D/F medium; Invitrogen) supplemented with 10\% fetal bovine serum (FBS; Hyclone) and $1 \%$ penicillin streptomycin (P/S; Invitrogen; D/F-FBS). Medium was changed every $2 \mathrm{~d}$. Dissociated OECs were maintained in vitro for $5 \mathrm{~d}$ and then immunopurified using p75-nerve growth factor receptor (anti-p75-NGFR, 1:5; clone 192; Chandler et al., 1984). Purified OECs were maintained in vitro for an additional $7 \mathrm{~d}$ and received D/F-FBS medium supplemented with pituitary extract $(20 \mu \mathrm{g} / \mathrm{ml}$; Invitrogen) and forskolin ( $2 \mu \mathrm{M}$; Sigma-Aldrich). Mitogens were withdrawn from cells 1-2 d before transplantation or use in neurite outgrowth experiments. Samples of OEC preparations were stained with antibodies against p75-NGFR (1:5; clone 192), S100 (1:1000; Dako), or Sox10 (1:100; R\&D Systems).

Fibroblast cell cultures. Skin biopsies from the abdominal wall were dissociated into fibroblast cultures as described by Takashima (2001). The dermis was separated mechanically from the epidermis and hypodermis. Dermal tissue was trypsinized $(0.3 \%)$ for $10 \mathrm{~min}$ at $37^{\circ} \mathrm{C}$, and rinsed with D/F-FBS medium. Cells were centrifuged at $365 \times g$ for $5 \mathrm{~min}$ before the pellet was resuspended and incubated in $12.5 \mathrm{mg} / \mathrm{ml}$ collagenase (Invitrogen) for $1 \mathrm{~h}$ at $37^{\circ} \mathrm{C}$. The collagenase-cell mixture was filtered using a cell strainer, centrifuged, and then resuspended in D/F-FBS supplemented with Primocin $(0.1 \mathrm{mg} / \mathrm{ml}$; InvivoGen). Primary FBs were plated on culture flasks, maintained at $37^{\circ} \mathrm{C}$ with $5 \% \mathrm{CO}_{2}$, and the medium was changed every $2 \mathrm{~d}$. FBs were passaged one to two times before cell transplantation (12-14 d in vitro).

Cortical neurite outgrowth assay. For in vitro neurite outgrowth experiments, wild-type or GFP-labeled OECs first were seeded at a concentration of 32,000-35,000 cells onto 4-well glass slides pre-coated with poly-L-lysine 
(PLL; $0.05 \mathrm{mg} / \mathrm{ml}$; Sigma-Aldrich) $5 \mathrm{~d}$ after immunopurification. After $48 \mathrm{~h}$, cortical neurons were isolated and pipetted into the center of each well. Cortical neurons were obtained from postnatal day 8 rat cerebral cortices. After removal of the leptomeninges, cerebral cortices were harvested in $\mathrm{Hi}$ bernate-A medium (BrainBits) with $\mathrm{P} / \mathrm{S}$, L-glutamine (L-glu; Invitrogen), and B27 supplement (Invitrogen). Cortices were chopped and digested with warm papain $(2 \mathrm{mg} / \mathrm{ml}$; Worthington) in Hibernate-A medium with $\mathrm{P} / \mathrm{S}$ and L-glu. Neurons were enriched with an OptiPrep step gradient (AxisShield), resuspended in Neurobasal medium (Invitrogen), and counted before they were added to the positive control, pre-coated laminin + PLL (Laminin $10 \mu \mathrm{g} / \mathrm{ml}$; Invitrogen), the neutral control, PLL only $(0.05 \mathrm{mg} / \mathrm{ml}$ ), or either wild-type or transgenic OECs + PLL wells at a concentration of 100,000 cells per well.

After plating the cortical neurons, cultures were maintained for an additional $24 \mathrm{~h}$. Cultures were fixed in $4 \%$ paraformaldehyde for $15 \mathrm{~min}$, washed with buffer, and neurons were visualized with anti- $\beta$-3-tubulin (1:1500; Covance). Three independent culture experiments were conducted, and two wells per experiment per variable were analyzed. Approximately 10 randomly selected $0.1296 \mathrm{~mm}^{2}$ fields were acquired per well using a Zeiss LSM 510 confocal microscope for neurite outgrowth analysis. Neuronal cell bodies and all neurites were traced using Neurolucida software (v10.31, MicroBrightField) and then individual neurite lengths and cell body details were exported to Microsoft Excel using Neurolucida Explorer 10.31.

Surgical procedures: spinal cord injury and cell transplantation. All surgeries were performed under aseptic conditions with the rats deeply anesthetized with isoflurane gas administered via facemask. A skin incision was made at vertebral levels T6 to L1, the paravertebral muscles were retracted, and partial laminectomies at T8 and T9 were performed. The dorsal dura was incised longitudinally and then laterally at both ends to expose the spinal cord, while maintaining most of the lateral and ventral dura intact. The spinal cord then was completely transected at spinal level T9-T10 with micro-scissors. Two surgeons verified that the transection was complete. A total of 16 spinal rats were immunosuppressed with CSA beginning $3 \mathrm{~d}$ before the spinal cord transection and transplantation surgery and continued until the end of the study (Table 1).

FBs and OECs were harvested after a total of 12-14 d in vitro. Cells were rinsed with HBSS without $\mathrm{Ca}^{2+} / \mathrm{Mg}^{2+}$ and dissociated with $0.25 \%$ trypsin-EDTA. Following a medium rinse and centrifugation, cells were resuspended at a concentration of 100,000 cells per microliter in serumfree DMEM. A fresh cell preparation was made for each FB and OEC transplantation. FBs (29 rats) or OECs (32 rats) were injected stereotactically into the spinal cord $1 \mathrm{~mm}$ rostral and caudal to the lesion immediately after the spinal cord transection. Approximately 50,000 cells were transplanted into four midline injection sites within each spinal cord stump for a total of 200,000 cells per stump. Rats were placed in an incubator until fully responsive and then housed individually. Spinal rats received manual bladder expression three times daily for 2 weeks and then twice daily thereafter at $\sim 12 \mathrm{~h}$ intervals. All animals were inspected daily for weight loss and dehydration. Urine samples were tested weekly using Multistix 10 SG reagent strips (Siemens). Surgeons and investigators were blinded to treatment group from the time of transplantation throughout the remainder of the study.

Tissue preparation. Rats were anesthetized and intracardially perfused with $4 \%$ paraformaldehyde and postfixed for $2 \mathrm{~h}$ at $4^{\circ} \mathrm{C}$. Spinal cords were washed, dissected, cryoprotected with $30 \%$ sucrose, and embedded in OCT compound (Tissue-Tek). Spinal cords, including the injury site, were cryosectioned sagittally at a thickness of $25 \mu \mathrm{m}$; tissue sections were mounted in series onto 16 slides, and were stored at $4^{\circ} \mathrm{C}$ in Millonigs buffer with azide.

Immunohistochemical procedures. One slide containing every 16th section was incubated with primary antibodies against GFP (1:1000; Aves Laboratories), Glial Fibrillary Acidic Protein (GFAP; monoclonal 1:1000; BD Biosciences; polyclonal 1:10K; Dako), and one additional marker to identify neurons (NeuN, 1:1000; Millipore), serotonergic axons (5-HT, 1:5000; ImmunoStar), neurofilament (NF-H, 1:1000; Millipore), immune cells (Iba-1, 1:5000; Wako Chemicals), native chondroitin sulfate proteoglycans (CS-56, 1:200; Sigma-Aldrich), water channel aquaporin 4 (AQP4, 1:1000; Sigma-Aldrich), or fibronectin (FN; monoclonal 1:200;
BD Biosciences; polyclonal 1:1000; Dako). Sections were permeabilized and placed in species appropriate serum as a presoak (donkey, Jackson ImmunoResearch; or goat serum, Vector Laboratories) before incubation with primary antibodies overnight. To visualize immunostaining, species appropriate AlexaFluor 488, 555, 594, or 647 (1:100-500; Jackson ImmunoResearch) was used. Nuclei were stained with Hoechst dye (Sigma-Aldrich) for $5 \mathrm{~min}$ and sections were coverslipped with Fluorogel (Electron Microscopy Sciences).

Oil red and GFAP bright-field staining. Slide-mounted sections were washed with $\mathrm{ddH}_{2} \mathrm{O}$ for 5 min and rinsed with $70 \%$ ethanol for 5 min. Sections were incubated with Oil Red O stain $(700 \mathrm{mg}$ of Oil Red powder dissolved in $100 \mathrm{ml}$ of $70 \%$ ethanol, filtered twice, Sigma-Aldrich) for 30 min, and again washed with ethanol for $1 \mathrm{~min}$ and $\mathrm{ddH}_{2} \mathrm{O}$ for $5 \mathrm{~min}(\mathrm{Ma}$ et al., 2002). Sections were rinsed with $0.1 \mathrm{~m}$ Tris containing $1.4 \% \mathrm{NaCl}$ and $0.1 \%$ BSA followed by $15 \mathrm{~min}$ in $0.1 \%$ Triton detergent buffer. Sections were incubated in 5\% donkey serum containing 0.1\% Triton before incubation with anti-GFAP overnight. Sections were incubated in Tris buffer with a biotinylated rabbit secondary antibody, amplified by incubation with avidin-biotin complex, and visualized using diaminobenzidine (Dojindo Laboratories).

Lesion site analyses. All anatomical analyses were conducted blind to cell transplant type. Photomicrographic montages of spinal cord sections were taken with an Olympus AX70 microscope and Zen 2012 image capture software (Carl Zeiss) with the panorama module. Confocal images were obtained with a Zeiss LSM 510 or 800 microscope and $25 \times$ or $63 \times$ oil objective. Analyses and $3 \mathrm{D}$ visualization were conducted with the Neurolucida and Neurolucida Explorer software (v10, MicroBrightField). To determine the survival and migration of transplanted FBs and OECs, we traced the GFP-positive area in the lesion core and stumps in every eighth section. The percentage of GFP-positive cells in the lesion core is reported as the volume of GFP in the lesion core divided by the total volume of GFP within the lesion core plus stumps. To determine FB and OEC filling of the lesion core, the areas of GFP-labeled cells and fibronectin-positive extracellular matrix in the lesion core were measured in every 16th section of the spinal cord to calculate volumes as described by Kubasak et al. (2008). We report the percentage of GFP-positive cells that fill the GFAPnegative lesion volume.

To determine the extent of neuronal preservation, the length of the nonneuronal tissue was quantified as by Takeoka et al. (2011). For every eighth section, the distance between the neuron closest to the rostral and caudal GFAP-positive stumps was measured along with the total distance of the non-neuronal tissue and lesion core. To determine the preservation of axons postinjury, we analyzed serotonergic axons present in the rostral stump associated with the GFAP border in every 16th section. Axon sparing was measured as follows: (1) the number of 5-HT-positive axons that crossed the GFAP-positive border into the lesion core, (2) the total area of 5-HT-labeled axons within the GFAP-negative lesion core, and (3) the distance from the rostral border to the most caudal 5-HT-labeled axon in the lesion core. Axons that did not extend beyond the GFAP-positive border (considered as zero) were reported as negative lengths.

To determine changes in immune cell activation, astrocyte reactivity, and CSPG deposition, mean luminance measurements for Iba-1, GFAP, and CS-56 immunoreactivity, respectively, were acquired from images of every 16th section. Images were gathered under identical exposure conditions and used to evaluate the mean pixel luminance from individual channels using the Zen 2012 annotations/measurements feature. For the Iba- 1 analysis, five zones were marked by rectangles $\left(500,000 \mu \mathrm{m}^{2}\right)$ on the image and labeled as follows: rostral stump, rostral border, lesion core, caudal border, or caudal stump. Luminance measurements for the CS-56 analysis were taken from eight zones marked by squares $(\sim 6500$ $\mu \mathrm{m}^{2}$ ) within the GFAP-positive rostral and caudal borders and GFAPnegative lesion core. Additional luminance measurements for CS-56 were taken from eight zones with GFP-FBs, GFP-OECs, and adjacent zones without GFP cells. Rectangles were aligned with the GFAP-positive border and cysts were avoided. As a control, the GFAP luminance also was measured in the same Iba- 1 and CS-56 zones. Mean luminance intensity measurements made for Iba-1, GFAP, and CS-56 immunoreactivity were normalized to background auto-fluorescence of each sec- 
tion. Results are presented as a fold-change from background levels and luminance values were averaged across zones for each animal.

Myelin phagocytosis assay. Purified p75-NGFR-positive OECs were plated at a concentration of 25,000 cells onto PLL-coated 15-mm-round coverslips and left to adhere overnight. OECs were pretreated with CellTracker Green CMFDA ( $7 \mu \mathrm{M}$; Invitrogen) and allowed to recover for $24 \mathrm{~h}$. Myelin was prepared as described previously (Colman et al., 1982; Zheng et al., 2003; Runyan and Phelps, 2009). Myelin was mixed with D/F-FBS media, added to OEC-coated coverslips at a final concentration of $0.1 \mathrm{mg} / \mathrm{ml}$, and left to incubate at $37^{\circ} \mathrm{C}$ for $1 \mathrm{~h}$. Coverslips were rinsed with media to remove excess myelin, fixed with $4 \%$ paraformaldehyde for $30 \mathrm{~min}$, and washed three times with PBS before immunocytochemical staining. OECs were permeabilized using $5 \%$ Triton X-100 solution (Sigma-Aldrich), blocked with normal donkey serum, and incubated overnight with anti-myelin basic protein (MBP; 1:250; Millipore). To visualize immunostaining, cells were incubated with donkey anti-chickIgY-Rhodamine (1:500, Jackson ImmunoResearch) for $1 \mathrm{~h}$. Coverslips were mounted onto glass slides with Fluorogel. Images were obtained using a Zeiss LSM 510 confocal microscope and $63 \times$ objective.

Statistical analyses. Measurements from each analysis were averaged to obtain a mean for each animal. The mean values for each rat were combined into a group mean for each time point and reported as mean \pm SEM. All statistical comparisons were performed with JMP Software (v10.0.0 for Microsoft Windows, SAS Institute) or R (3.2.2; R Core Team, 2015). A two-way ANOVA was conducted to compare the pooled effects of time and cell transplant groups. To compare group means across time points MANOVA followed by a two-way ANOVA was used. Post hoc tests (Student's $t$ tests) were performed when interactions were observed. In the case where the sample size was small, 95\% confidence intervals were generated by Monte Carlo simulation and significance was tested by nonparametric, Bootstrap approximation of a two-way repeatedmeasures ANOVA. Statistical significance was determined at ${ }^{*} p<0.05$, ${ }^{* *} p<0.01$, and ${ }^{* * *} p<0.001$.

\section{Results}

Wild-type and GFP-OECs have similar growth promoting abilities

OECs are unique glia of the olfactory system, but they express markers common to astrocytes, oligodendrocytes, and Schwann cells. No OEC-specific marker is currently available. To identify transplanted cells in this study, we derived OECs from GFPlabeled rats generated by random transgene integration into the genome. To assess whether OECs cultured from GFP-expressing rats (GFP-OECs) differed from those derived from wild-type nontransgenic rats, we examined GFP-OECs for expression of typical markers. Most GFP-OECs expressed established OEC markers (89\% p-75-NGFR; 96\% S100; 100\% Sox10). We then compared the growth promoting abilities of wild-type OECs with GFP-OECs. We cultured postnatal cortical neurons on: (1) laminin (positive control), (2) PLL (neutral substrate), (3) PLL and OEC, and (4) PLL and GFP-OEC. Neurites grew long processes when cultured on laminin, but had limited outgrowth on the PLL substrate alone (mean neurite length on: laminin $146 \pm$ $31 \mu \mathrm{m}$; PLL $54 \pm 9 \mu \mathrm{m} ; p=0.0014)$. The addition of OECs or GFP-OECs significantly enhanced neurite outgrowth compared with PLL alone (OEC $117 \pm 19 \mu \mathrm{m}, p=0.0114$; GFP-OECs $118 \pm 29 \mu \mathrm{m}, p=0.0111)$. Because neurite outgrowth did not differ between OECs and GFP-OECs $(p=0.986)$ the random GFP gene insertion does not appear to alter the growth promoting effects of OECs.

\section{OECs survive longer than FBs after transplantation}

Transplanted FBs and OECs survived and migrated from the GFAP-positive rostral and/or caudal stumps into the lesion core during the first week postinjury (Fig. 1A,B; Table 1). During week 1 , the transplanted cells appeared healthy and maintained their differences in size and cellular morphology (Fig. 1G,H). Ovoid-shaped FBs formed a contiguous carpet-like arrangement, occupying a larger area than spindle-shaped OECs that aligned into tubular networks (Fig. $1 G, H$ ). By 2 weeks, there was a clear loss of cells in the lesion core as FBs and OECs survived primarily within the spinal cord stumps (Fig. 1C,D). Additionally, GFPpositive debris was found in the lesion core and the stumps at 2 and 4 weeks postinjury, consistent with graft cell death. By 4 weeks, none of the rats transplanted with FBs had GFP-labeled cells, whereas OECs survived in five of eight rats (Fig. 1E,F). Of those five rats with OECs, two rats had OECs in the rostral and caudal stumps and three had the majority of OECs in the lesion core (Fig. $1 F)$. Interestingly, more OECs survived in the lesion core at 4 than at 2 weeks (Fig. 1, compare $D, F$ ). Finally, a few OECs were found within the stumps, but none remained in the lesion core at 8 weeks (data not shown). These data suggest that OECs survive longer than FBs after transplantation.

To estimate FB and OEC survival and migration, the volume of GFP-labeled cells in the lesion core divided by the total volume of GFP in the spinal cord was reported as a percentage. At 1 week a large percentage of the GFP-labeled cells were found in the lesion core (Fig. 1J; FB $72 \pm 5 \%$ vs OEC $79 \pm 4 \%$ ). The decrease in survival of transplanted cells in the lesion core at 2 weeks was remarkable (Fig. 1J; FB $3 \pm 3 \%$ vs OEC $14 \pm 7 \%$ ). By 4 weeks, GFP-labeled cells were found only in the lesion core of OECtreated rats (Fig. $1 J$; FB $0 \%$ vs OEC $23 \pm 14 \% ; p=0.0381$ ). This finding indicates that OECs continue to migrate into the lesion core between 2 and 4 weeks.

When in the lesion core, FBs formed a continuous sheet of cells, whereas OECs interacted in delicate trabecular-like networks (Fig. $1 G-I$ ). To measure the extent that FBs and OECs filled the lesion core, the volume of GFP-labeled cells was divided by the volume of the fibronectin-positive extracellular matrix in the lesion core and reported as a percentage. FBs filled $\sim 83 \pm$ $17 \%$ of the lesion at 1 week, but at 2 weeks few FBs remained $(3 \pm$ $3 \%)$. OECs filled $34 \pm 6 \%$ of the lesion volume at 1 week, and by 2 weeks, only $\sim 1 \%$ of the lesion volume contained OECs. Interestingly, by 4 weeks OECs likely migrated from the stumps into the lesion core as they now filled $8 \pm 5 \%$ of the lesion volume. These data suggest that FBs initially fill more of the lesion core than OECs, but this difference is not maintained over time.

\section{OECs reduce neuronal degeneration after a spinal cord transection}

We next asked whether OEC transplantation had long lasting effects on neuronal survival. To determine whether OECs help preserve neurons, we measured the shortest distance between the astroglial scar border and NeuN-labeled neuronal cell bodies in the rostral and caudal stumps (Fig. 2A). The distance between the GFAP border and the nearest neuron did not differ between the rostral and caudal stumps and thus values from the two stumps were combined to obtain the average neuron-free distance in the stumps. Neuronal cell bodies were located closer to the astroglial scar border in OEC- than in FB-transplanted rats at 1 and 2 weeks (Fig. $2 C$; 1 week FB $1.2 \pm 0.1$ vs OEC $0.5 \pm 0.1 \mathrm{~mm}, p=0.0502$; 2 week FB $1.9 \pm 0.5$ vs OEC $0.6 \pm 0.2 \mathrm{~mm}, p=0.0004)$. In addition, during the first 2 weeks the total distance between the closest rostral and caudal stump neurons was shorter in OECcompared with FB-treated spinal cords (Fig. 2D; 1 week FB $7.2 \pm$ 0.3 vs OEC $5.2 \pm 0.3 \mathrm{~mm}, p=0.0024 ; 2$ week FB $7.4 \pm 1$ vs OEC $4.1 \pm 0.6 \mathrm{~mm}, p=0.0272)$. Although the extent of neuronal survival did not differ between transplant groups at 4 weeks, we observed spinal cord neurons ensheathed by GFP-positive OECs 
FB
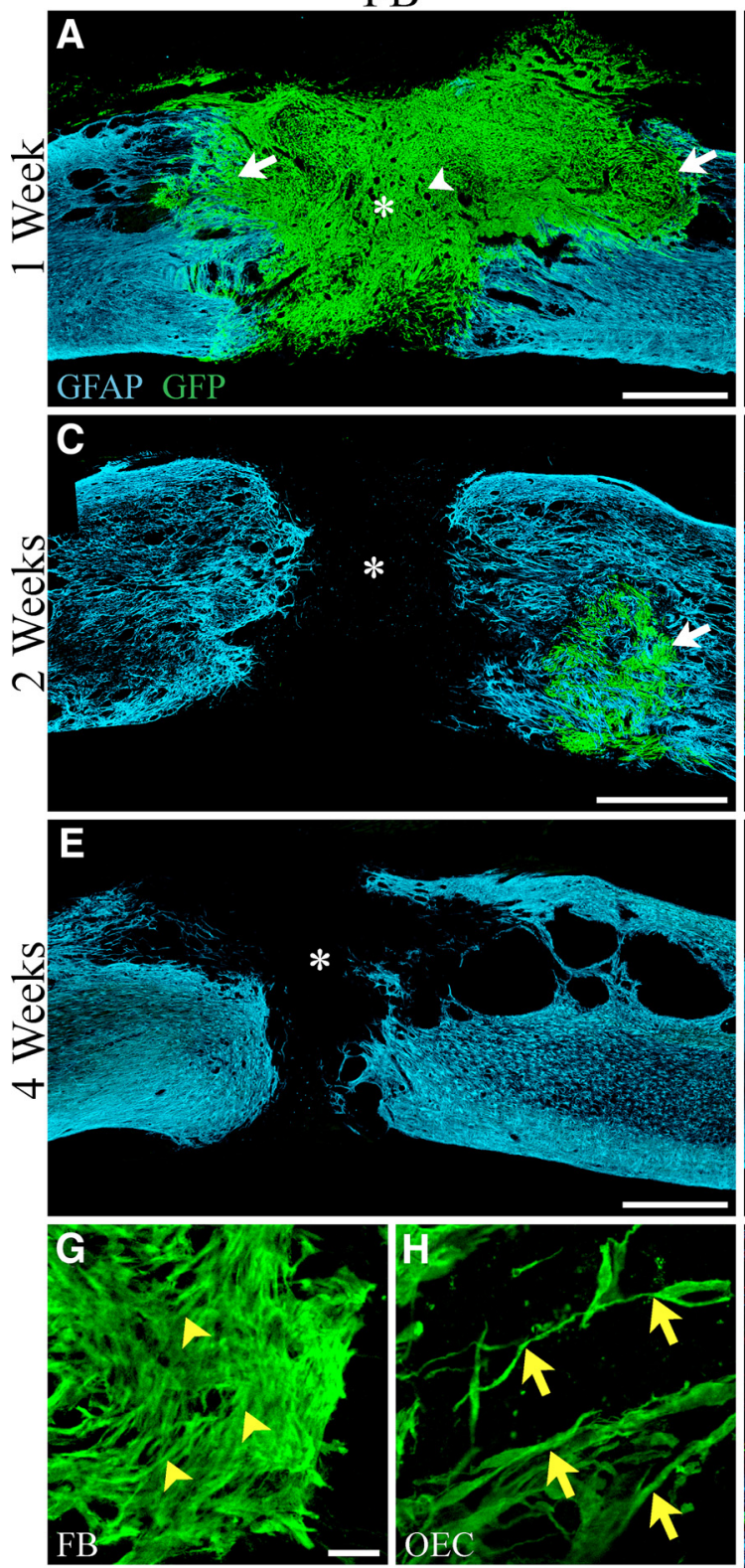

J 100

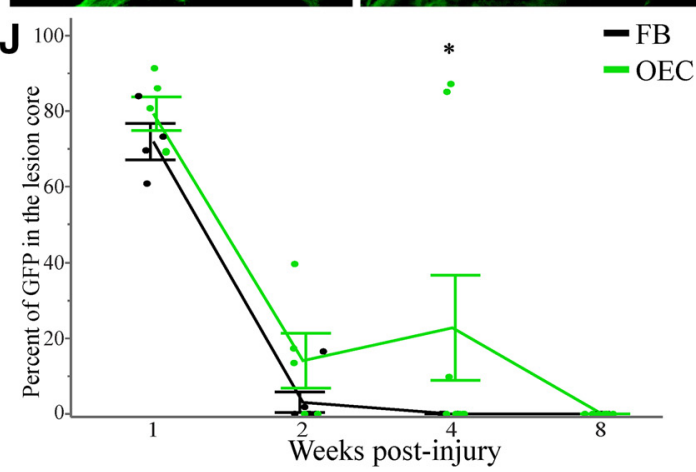

OEC
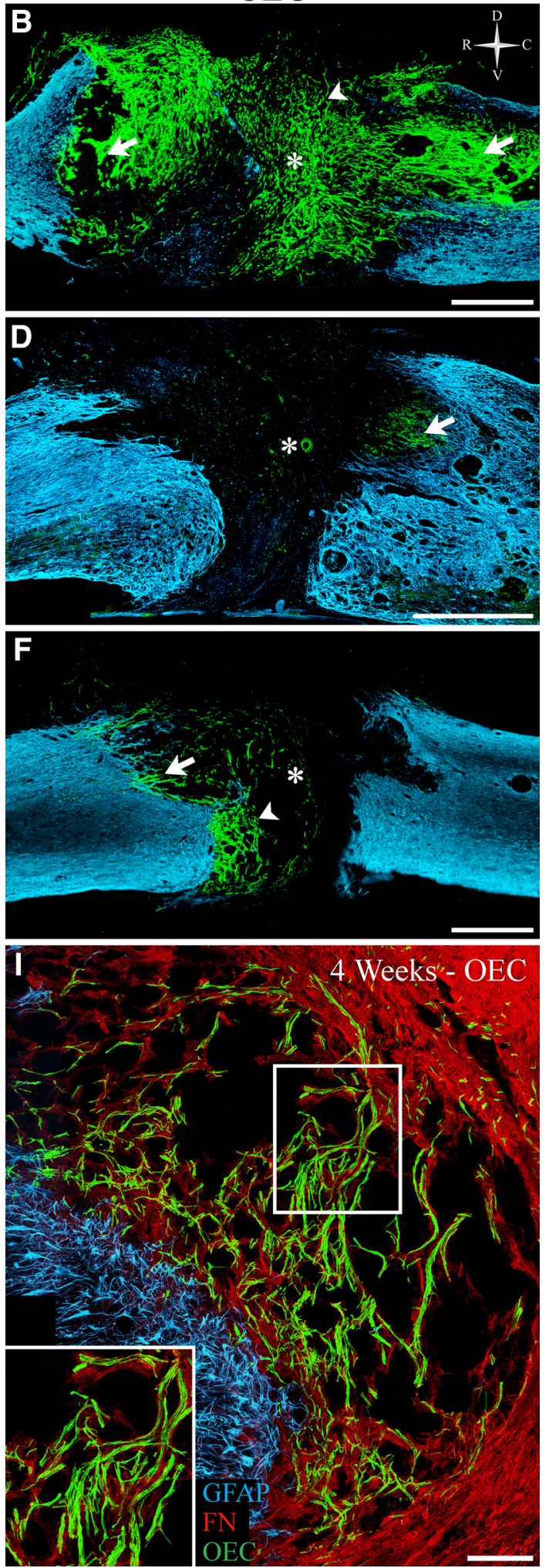

Figure 1. Survival and migration of transplanted cells. $\boldsymbol{A}-\boldsymbol{F}$, GFP-labeled FBs $(\boldsymbol{A}, \boldsymbol{C}, \boldsymbol{E})$ or $\mathrm{OECS}(\boldsymbol{B}, \boldsymbol{D}, \boldsymbol{F})$ were present within the lesion core (asterisks) and/or GFAP-positive (cyan) rostral and caudal stumps between 1 and 4 weeks after spinal cord transection and cell transplantation. Anti-GFP immunolabeling identified large numbers of engrafted FBs and OECs in the lesion core (white arrowheads) and stumps (white arrows) at 1 week post-transplant $(\boldsymbol{A}, \boldsymbol{B})$. At 2 weeks, neither FBs nor 0ECs survived in the lesion core, but GFP-positive cells are present in the stumps ( $\boldsymbol{C}, \boldsymbol{D}$, white arrows). At 4 weeks no FBs survived (E), whereas 0 ECs are present in the lesion core (white arrowhead) and stumps (F, white arrow). Neither FBs nor 0 ECS survived at 8 weeks (data not shown). $\boldsymbol{G}$, $\boldsymbol{H}$, Confocal images show engrafted FBs $(\boldsymbol{G})$ as dense sheets of cells (yellow arrowheads), whereas 0 ECs $(\boldsymbol{H})$ formed thin tubular tracks of cells (yellow arrows). $\boldsymbol{I}$, Confocal image shows intermingled spindle-shaped $0 \mathrm{ECS}$ (inset) at 4 weeks postinjury within a trabecular network of fibronectin-positive (red) extracellular matrix in the lesion core. $J, 0 E C$ migrate and occupy more of the lesion core relative to the total GFP volume than FBs at 4 weeks postinjury, but do not differ at other time points. Circles represent individual animals and group mean $\pm S E M$ values are shown in black for FBs and green for $0 \mathrm{ECS}$ in this and subsequent figures. All sagittal spinal cord images are oriented with rostral to the left and dorsal to the top. Scale bars: $\boldsymbol{A}-\boldsymbol{F}, 1 \mathrm{~mm} ; \mathbf{G}, \boldsymbol{H}, 50 \mu \mathrm{m} ; \boldsymbol{I}, 200 \mu \mathrm{m}$. 
but not FBs in the lesion core (Fig. $2 B$ ). Thus, OEC transplantation promotes neuronal survival in the stumps and protects the surviving neurons within the lesion core.

OEC transplants reduce axonal dieback after a spinal cord transection

Immediately after a spinal cord injury, astrocytes become reactive and orient their processes to seal off the lesion, thereby blocking the "pathways" which potentially could provide routes for regenerating axons ( $\mathrm{Li}$ et al., 2005b). To assess whether or not OEC transplantation could preserve axons we identified the raphespinal tract, ie, descending serotonergic (5-HT) axons important for locomotion, in FB- and OEC-treated spinal cords. Previously we found that 5-HT axons extended from the rostral stump into the lesion core after a complete spinal cord transection usually originated from the raphespinal tract than intraspinal 5-HT neurons (Takeoka et al., 2011). Following OEC treatment, multiple 5-HT axons coalesce and associate with astrocytes at the GFAP-positive border (Fig. 3C,D). These 5-HT bundles align with astrocytes exhibiting rostrocaudally orientated processes that effectively provide "pathways" for severed axons to regenerate (Fig. 3C,D). Conversely, in FB-treated spinal cords astrocytic processes are oriented perpendicular to the rostrocaudal axis and apparently limit the extension of 5-HT axons into the lesion core (Fig. $3 A, B$ ). We quantified the total number of 5-HT axons that aligned with astrocytes and crossed the scar border and found fewer axons in FB than OEC groups averaged across all time points (FB $8 \pm 7$ vs OEC $31 \pm 14$ axons, $p=$ $0.0045)$. At the first week the total number of 5-HT axons was twofold greater in OEC- than FB-treated rats (Fig. 3G; FB $29 \pm 9$ vs OEC $72 \pm 22$ axons, $p=0.0045)$. More axons also crossed the rostral border in OEC- than FBtreated rats at 2 weeks (Fig. 3G; FB $1 \pm 1$ vs OEC $32 \pm 6$ axons, $p=0.0231)$. This finding suggests that OECs preserve 5-HT axons and may modulate the configuration of astrocytes at the scar border to promote the extension of 5-HT axons into the lesion core.

In addition to the number of 5-HT axons that crossed the astrocyte border, we also asked whether more 5-HT axons were found in the lesion core of OEC- than FBtreated rats. Because individual 5-HT axons could not be clearly distinguished, we measured the area of the lesion core that contained 5-HT axons. Larger areas of the OEC than the FB lesion cores had 5-HTpositive axons at 2 weeks (Fig. $3 A, B$; FB $781 \pm 641$ vs OEC 12,020 $\pm 5342 \mu \mathrm{m}^{2}$, $p=0.0267)$. We also assessed how far into the lesion core the 5-HT axons persisted.
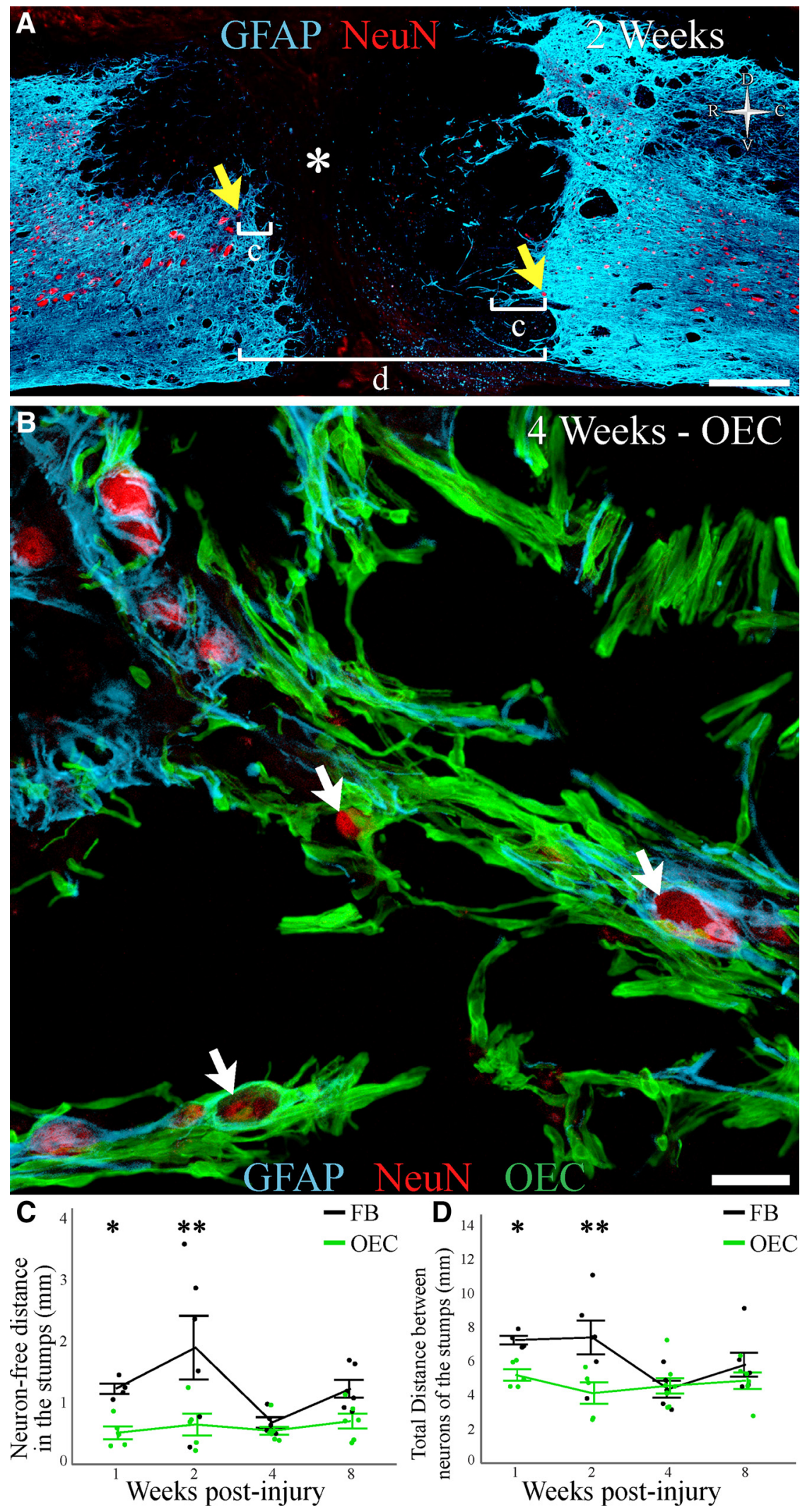

Figure 2. OECs reduce neuronal degeneration. $A$, At 2 weeks postinjury an $0 \mathrm{EC}-$ transplanted spinal cord has the astroglial scar border identified with GFAP (cyan) and neurons (yellow arrows) marked with NeuN (red). No OECs were present in this section. The distance between neurons (yellow arrows) and the nearest astrocyte scar border (c) and the total distance between rostral and caudal neurons (d) were measured. $\boldsymbol{B}$, Confocal image near the rostral scar border contains neurons (white arrows) ensheathed by $0 \mathrm{EC}$ s within the lesion core at 4 weeks postinjury. $\boldsymbol{C}, \boldsymbol{D}$, The neuron-free regions in the rostral and caudal stumps $(\boldsymbol{A}, \boldsymbol{c})$ and the total distance between the neurons of the rostral and caudal stumps $(\boldsymbol{A}, \mathrm{d})$ were greater in FB- than $0 \mathrm{EC}$-treated rats at 1 and 2 weeks postinjury. Scale bars: $\boldsymbol{A}, 500 \mu \mathrm{m} ; \boldsymbol{B}, 50 \mu \mathrm{m}$. 

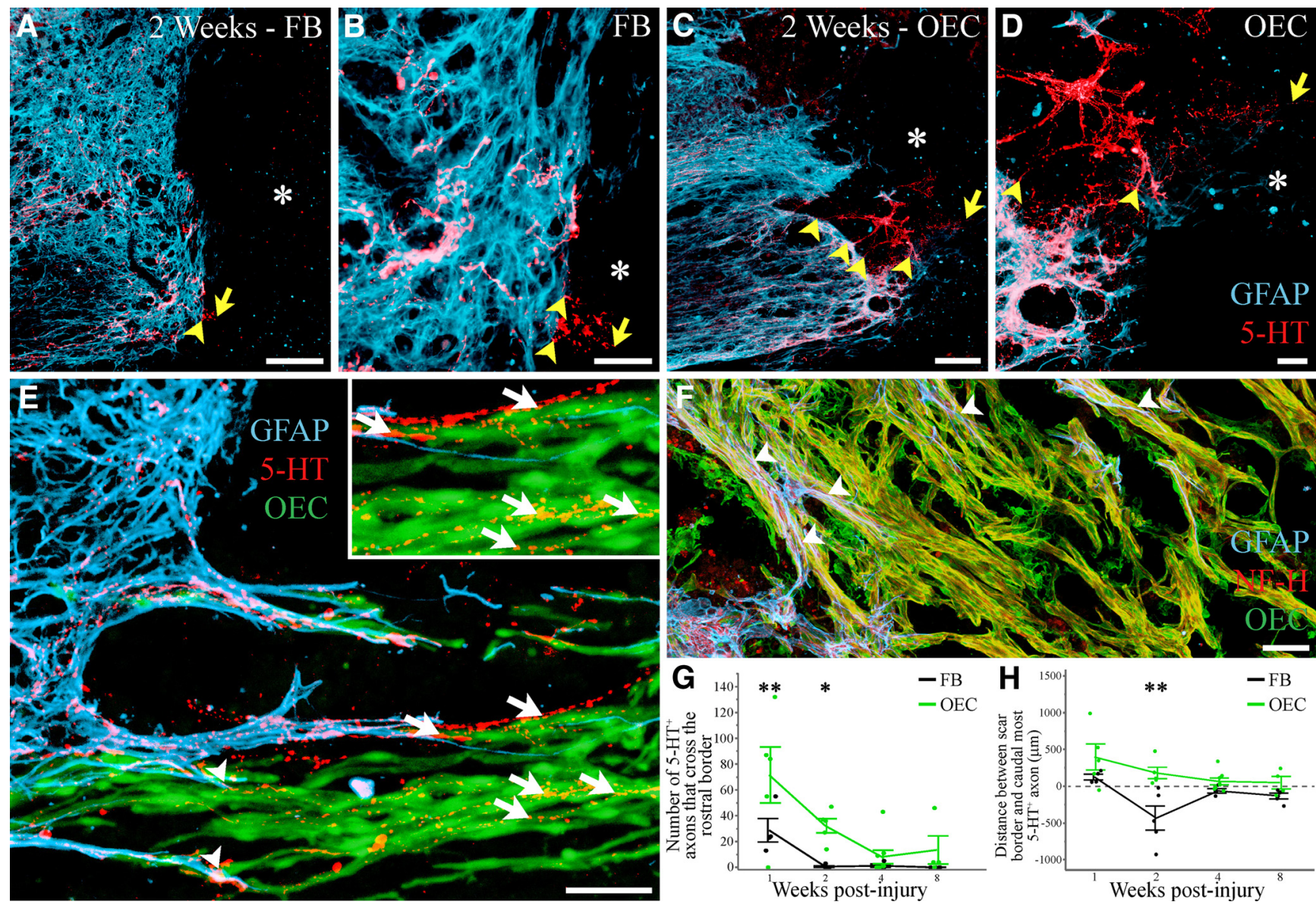

Figure 3. OECs reduce serotonergic axonal dieback. $\boldsymbol{A}-\boldsymbol{D}$, Representative images $(\boldsymbol{A}, \boldsymbol{C})$ and enlargements $(\boldsymbol{B}, \boldsymbol{D})$ show serotonergic axons (5-HT, red) that extend across (yellow arrowheads) the GFAP-positive rostral border and into the lesion core ( ${ }^{*}$, yellow arrows) in FB- $(\boldsymbol{A}, \boldsymbol{B})$ and OEC-transplanted $(\boldsymbol{C}, \boldsymbol{D})$ spinal cords. $\boldsymbol{E}$, Confocal image shows that 5 -HT axons bundle together, cross the astroglial scar border (white arrowheads), align with OECs (white arrows), and extend into the GFAP-negative lesion core (inset). $F$, Groups of OECs (green) colocalized with bundles of NF-H-positive axons (red) and astrocytes (cyan) provided scaffolds for OECs and axons to extend beyond the scar border (white arrowheads). $\boldsymbol{G}, \boldsymbol{H}, 0 \mathrm{O}$ average, more 5-HT-labeled axon bundles cross the rostral border in $0 \mathrm{EC}$ - than $\mathrm{FB}$-treated rats at 1 and 2 weeks postinjury $(\mathbf{G})$. The distance between the scar border and the most caudally extending 5 -HT axon was greater in $0 \mathrm{EC}-$ than FB-treated rats at 2 weeks $(\boldsymbol{H})$. Scale bars: $\boldsymbol{A}, \boldsymbol{C}, 200 \mu \mathrm{m} ; \boldsymbol{B}, \boldsymbol{D}-\boldsymbol{F}, 50 \mu \mathrm{m}$.

We measured the distance between the most caudal 5-HT axon and the rostral GFAP-border. On average, 5-HT axons tended to project further into the lesion core of OEC- compared with FBtreated cords at 1 week (Fig. $3 H$; FB $173 \pm 38$ vs OEC $438 \pm 172$ $\mu \mathrm{m}, p=0.0757)$. At 2 weeks, the 5 -HT axons in FB-treated rats exhibited dieback into the rostral stump as indicated by a negative value, whereas they extended further into the lesion core of OEC-treated rats (Fig. $3 H ; \mathrm{FB}-371 \pm 161$ vs OEC $227 \pm 76 \mu \mathrm{m}$, $p=0.0001)$. At 4 weeks, the 5-HT axons that extended beyond the astroglial scar border aligned with OECs (Fig. 3E).

We then used anti-NF-H to identify axons in the injury site and found that groups of OECs colocalized with bundles of axons that extended past the rostral scar border at 4 weeks (Fig. $3 F$ ). Additionally, reactive scar-forming astrocytes provided scaffolds for OECs and axons that projected into the lesion core (Fig. $3 F$ ). In sum, these data suggest that OECs help preserve axons in the lesion core, reduce axonal dieback compared with FBs, and form extensions of astrocytes at the scar border to provide pathways for axons to enter the lesion core.

OECs reduce inhibitory factors at the injury site

To determine whether OECs modify the inhibitory environment of the injury site, we asked if they could reduce inhibitory factors, such as CSPGs and myelin debris. We measured CS-56 immuno- fluorescence to quantitate CSPGs in the lesion core and adjacent astroglial scar border in FB- and OEC-treated spinal cords. Overall in the lesion core, the mean CS-56 luminance was greater in FB- than OEC-treated rats across all time-points (FB $3.2 \pm 0.2$ vs OEC $1.6 \pm 0.1, p=0.0001)$. Measurements of the mean CS-56 values yielded a similar cell transplant effect in the rostral and caudal stumps (FB $2.2 \pm 0.1$ vs OEC $1.2 \pm 0.1, p=0.0001$ ).

To examine the difference in CSPG expression over time, we compared CS-56 immunoreactivity at different time-points. The mean CS-56 luminance was greater in the lesion core of FBversus OEC-treated spinal cords at 2 (Fig. $4 A-C$ ), 4 , and 8 weeks postinjury (Fig. $4 C$; 2 week FB $3.2 \pm 0.1$ vs OEC $1.2 \pm 0.1, p=$ $0.0001 ; 4$ week FB $2.7 \pm 0.3$ vs OEC $1.9 \pm 0.1, p=0.0218 ; 8$ week FB $3.9 \pm 0.5$ vs OEC $1.4 \pm 0.2, p=0.0013$ ). The lesion core contained more CS-56 immunoreactivity than the spinal cord stumps, but even in the rostral and caudal stump borders, CSPG levels were higher in FB- than OEC-treated spinal cords at 2 and 4 weeks (Fig. $4 A, B, D ; 2$ week FB $2.7 \pm 0.1$ vs OEC $1.2 \pm 0.1, p=$ $0.0001 ; 4$ week FB $2.1 \pm 0.3$ vs OEC $1.3 \pm 0.1, p=0.0002$ ). As a control, GFAP luminance was measured from the same regions in each section and did not differ between FB and OEC groups (data not shown). Thus, mean luminance intensity appears to be a reliable measure that demonstrates differences in CSPG levels between $\mathrm{FB}$ and $\mathrm{OEC}$ transplanted rats. 

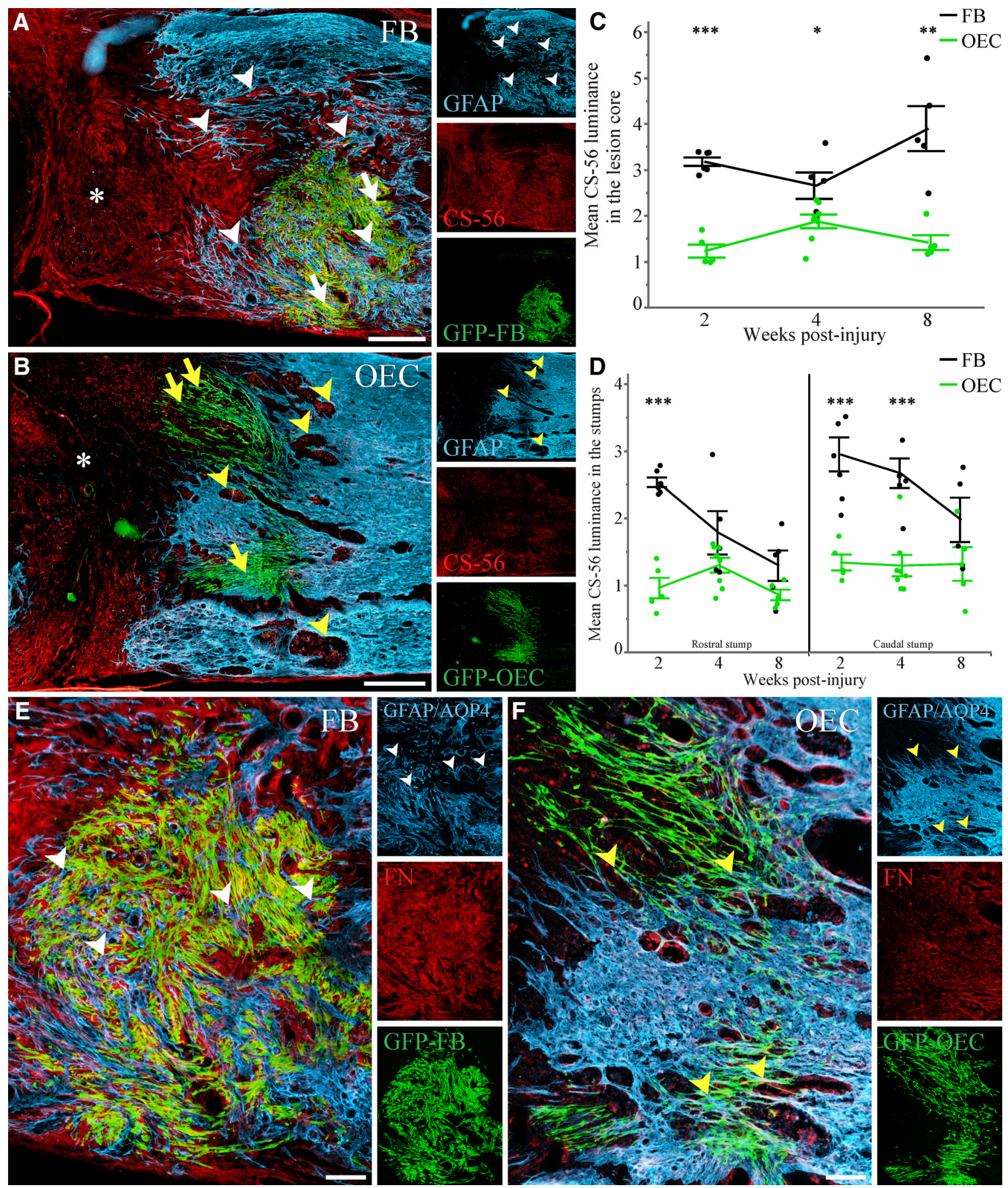

Figure 4. OECs reduce inhibitory CSPGs in the lesion core and facilitate astrocyte border formation. $A, B$, The spinal cord injury site and caudal stump border are labeled for astrocytes (GFAP, cyan), CSPGs (CS-56, red), and FBs ( $\boldsymbol{A}$, green) or OECs ( $\boldsymbol{B}$, green) at 2 weeks postinjury. FBs ( $\boldsymbol{A}$, white arrows) overlap with high levels of CSPG whereas OECs ( $\boldsymbol{B}$, yellow arrows) show the inverse. Astrocyte processes in OEC-treated spinal cords surround (SPG-positive cells ( $\boldsymbol{B}$, yellow arrowheads), a function not found in FB-treated rats ( $\boldsymbol{A}$, white arrowheads). Individual channels of the entire image are displayed on the right to show distribution of each antibody. $\boldsymbol{C}, \boldsymbol{D}$, The mean luminance of CSPGs was greater in the lesion core $(\boldsymbol{C})$ and the rostral and caudal stumps (D) of FB (black) than of OEC (green) transplanted spinal cords at 2, 4, and 8 weeks postinjury. $\boldsymbol{E}, \boldsymbol{F}$, Astrocyte morphology at the lesion border, shown by combined Aquaporin 4 (AQP4, cyan) and GFAP (cyan) staining, is altered in FB- $(\boldsymbol{E})$ but not $0 \mathrm{EC}$-treated $(\boldsymbol{F})$ spinal cords at 2 weeks postinjury. Astrocytic processes have a palisading arrangement when interwoven with $0 \mathrm{ECS}(\boldsymbol{F}$, yellow arrowheads), but appear compacted and disorganized with $\mathrm{FBs}(\boldsymbol{E}$, white arrowheads). High levels of fibronectin (red) are associated with $\mathrm{FBs}$ ( $\boldsymbol{E}$, individual channels), whereas fibronectin-positive cells are sequestered $(\boldsymbol{F}$, individual channels) by astrocytes (yellow arrowheads) in OEC-treated rats. Scale bars: $A, B, E, F, 200 \mu \mathrm{m}$. 

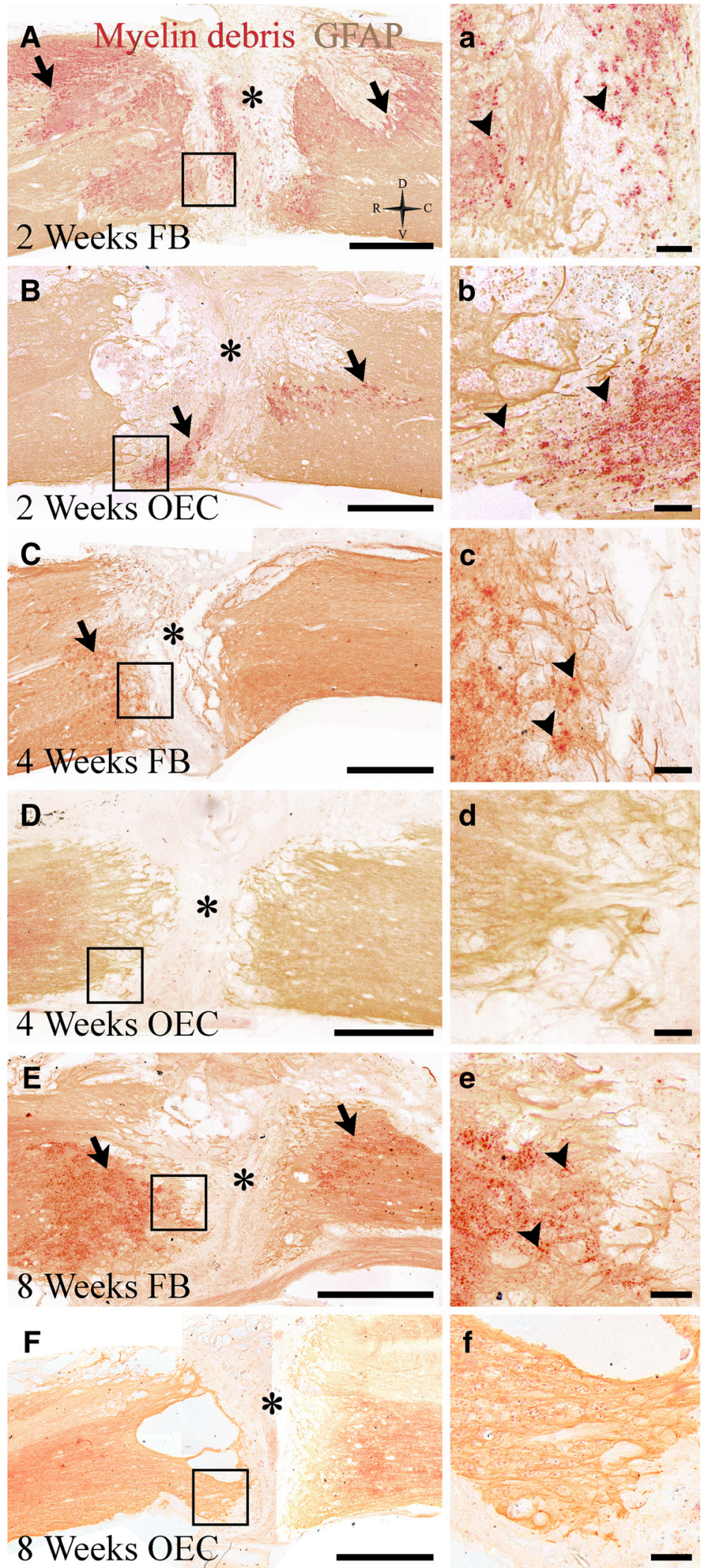

Figure 5. OECs reduce myelin debris at 2, 4, and 8 weeks postinjury. Distribution of 0il Red 0-labeled myelin debris (red puncta) in the lesion core $\left(^{*}\right)$ and stumps of FB- $(\boldsymbol{A}, \boldsymbol{C}, \boldsymbol{E})$ and $\mathrm{OEC}$-treated spinal cords $(\boldsymbol{B}, \boldsymbol{D}, \boldsymbol{F})$ is shown. The astroglial scar border is marked with GFAP (brown) immunostaining. $\boldsymbol{A}, \boldsymbol{B}$, At 2 weeks postinjury myelin debris (black arrows) extended beyond the lesion border and into the stumps in FB-treated $(\boldsymbol{A})$ rats, whereas less was found in $0 \mathrm{EC}$-transplanted $(\boldsymbol{B})$ rats $\boldsymbol{C}-\boldsymbol{F}$, Oil Red 0 -positive staining remains in and around the lesion site of FB- $(\boldsymbol{C}, \boldsymbol{E})$ but not $0 \mathrm{EC}$-treated $(\boldsymbol{D}, \boldsymbol{F})$ spinal cords at 4 and 8 weeks postinjury. $\boldsymbol{a}-\boldsymbol{f}$, Enlarged images of the boxed areas (insets) in $\boldsymbol{A}-\boldsymbol{F}$ show more red punctate myelin debris (arrowheads) in FB- than $0 \mathrm{EC}$-treated rats. Scale bars: $\boldsymbol{A}-\boldsymbol{F}, 1 \mathrm{~mm} ; \boldsymbol{a}-\boldsymbol{f}, 100 \mu \mathrm{m}$.
Next we assessed if the areas occupied by transplanted FBs or OECs showed different levels of CSPG luminance in the lesion core and stumps. At 2 weeks, we found a 50\% reduction in CS-56 luminance in areas directly occupied by OECs but not those associated with FBs (Fig. $4 A, B$, red channel; lesion core: FB $1.1 \pm$ 0.2 vs OEC $0.5 \pm 0, p=0.0415$; stumps: FB $1.1 \pm 0.1$ vs OEC $0.49 \pm 0.01, p=$ 0.0398 ). Interestingly, the astrocytic border was disrupted in FB-transplanted rats and higher levels of CSPG-labeling overlapped with the presence of FBs than OECs (Fig. $4 A, B)$. In the stumps of OEC-treated spinal cords, astrocyte processes encircled and sequestered CSPG-labeled cells within cavities (Fig. 4B, yellow arrowheads). Thus, OECs reduce inhibitory CSPGs at the injury site compared with FBs.

The altered astrocyte border formation seen in FB-treated rats prompted the comparison of astrocyte orientation and arrangement between the transplant groups. A closer examination of astrocytes, identified with both AQP4 and GFAP (Wanner et al., 2013), and GFP-labeled cells at the scar borders revealed that astrocytic processes were shorter and wider when in direct contact with FBs compared with OECs (Fig. $4 E, F)$. In OEC-treated spinal cords astrocytic processes have a palisading arrangement and intermingle with OECs (Fig. $4 F$ ). The disorganized astrocytes that interact with FBs overlap with highly fibronectinpositive areas (Fig. 4E). Low levels of fibronectin- or CSPG-positive cells also are sequestered in OEC- but not FB-treated spinal cords (Fig. 4A, B, E, F). These data imply that the astroglial scar border forms improperly after FB transplantation.

To determine whether OECs could alter the presence of myelin debris in and around the injury site, we used Oil Red O, a histological stain that identifies neutral lipids including myelin debris. Qualitatively we found more punctate Oil Red O-staining in FB- than OEC-treated rats. Myelin debris extended further into the rostral and caudal stumps of FB- than OEC-treated spinal cords at 2 weeks (Fig. $5 A, B)$. Oil Red $\mathrm{O}$ particulates appeared more abundant in the stumps and were not limited to the lesion core of FB- compared with OEC-treated rats (Fig. $5 a, b$ ). Myelin debris persisted in FB- but not OEC-treated spinal cords at 4 and 8 weeks (Fig. 5C-F), consistent with more demyelination in FB- than OEC-treated spinal cords. In combination, OEC transplantation can reduce two components of the inhibitory environment at the lesion site, CSPGs and myelin debris. 

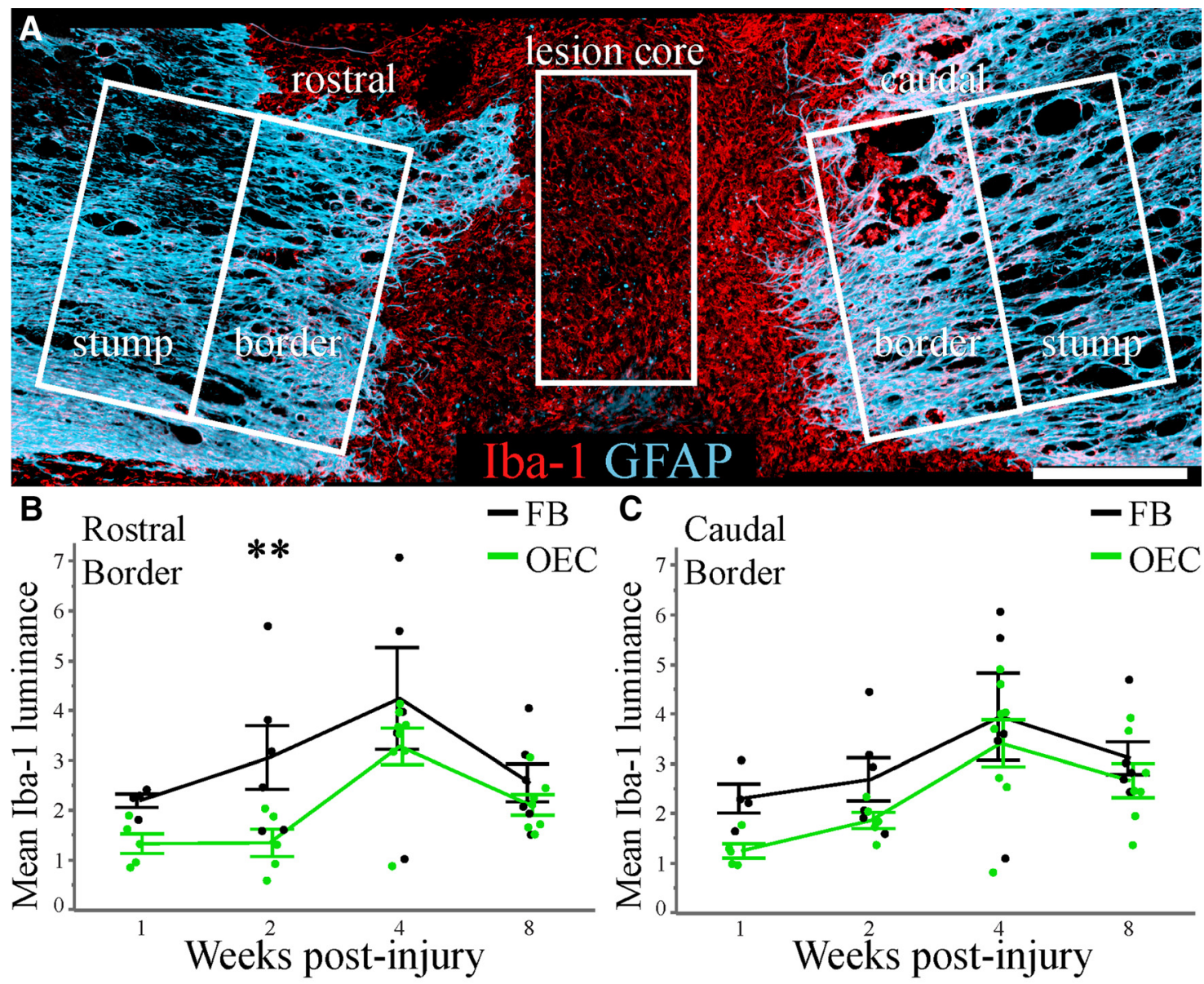

C Caudal

$-\mathrm{FB}$

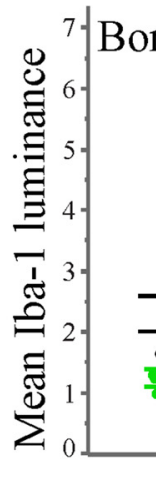

$-\mathrm{OEC}$
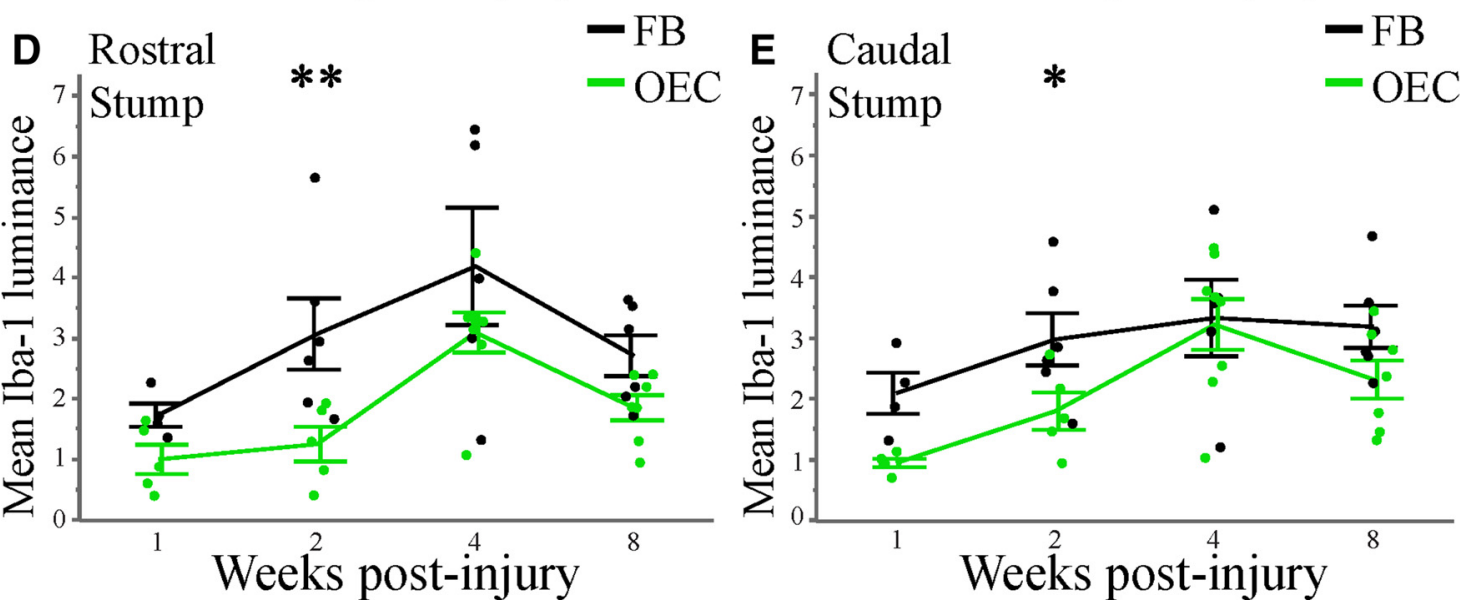

Figure 6. OECS reduce immune cell activation during the first 2 weeks postinjury. A, Lesion site of an OEC-transplanted spinal cord 2 weeks postinjury labeled for microglia/macrophages (Iba-1, red) and astrocytes (GFAP, cyan). 0 ECs were not present in this section. White boxes represent the zones in which Iba- 1 and GFAP immunofluorescence intensities were measured. $\boldsymbol{B}-\boldsymbol{E}$, Graphical representation of the mean Iba-1 luminance in the rostral border $(\boldsymbol{B})$, caudal border $(\boldsymbol{C})$, rostral stump $(\boldsymbol{D})$, and caudal stump $(\boldsymbol{E})$. At 2 weeks, Iba- 1 intensities were greater in FB- than $0 \mathrm{EC}-$-treated spinal cords. Scale bar: $A, 500 \mu \mathrm{m}$.

OECs reduce immune cell activation and infiltration after a complete spinal cord transection

Our results suggest that OECs mediate the survival of neurons and limit dieback of 5-HT axons, yet very few OECs survive 8 weeks after injury. Cell transplantation therapies are adversely affected by the immune response that peaks at 1 and 8 weeks after a spinal cord injury (Beck et al., 2010). To evaluate the interactions between transplant survival and activated microglial/ macrophages and astrocytes, antibodies against ionized calciumbinding adaptor molecule-1 (Iba-1) and a GFAP control were analyzed. We measured the mean Iba-1 and GFAP luminance in five zones: the rostral and caudal scar borders and stumps, and the lesion core (Fig. 6A). Iba-1 levels in the lesion core did not differ between FB- and OEC-transplanted rats at 1, 2, 4, and 8 weeks (data not shown). A sharp increase in Iba-1 luminance was observed, however, in the rostral border and stump of FB- compared with OEC-treated rats at 2 weeks (Fig. $6 B, D$; border FB $3.1 \pm 0.6$ vs OEC $1.3 \pm 0.3, p=0.0106$; stump FB $3.1 \pm 0.6$ vs OEC $1.3 \pm 0.3, p=0.0039)$. Iba-1 levels also were greater in the caudal stump of FB- compared with OEC-treated rats at 2 weeks 
(Fig. $6 E$; stump FB $3.0 \pm 0.4$ vs OEC $1.8 \pm 0.3, p=0.0318$ ). In OEC-transplanted spinal cords the increase in Iba-1 levels was delayed between 1 and 2 weeks in the rostral, but not the caudal border and stump (Fig. 6, compare slopes in $B, D$ to $C, E$ ). At 4 and 8 weeks the Iba- 1 levels in the borders and stumps were similar between the FB and OEC groups (Fig. 6B-E). As a control, GFAP luminance was measured from the same five zones delineated in Figure $6 A$ and never differed between FB and OEC groups (data not shown). These trends suggest that OECs delay and reduce the initial activation of Iba-1-positive immune cells.

Although GFAP luminance measurements did not vary with FB or OEC transplantation, a close examination of the scar borders revealed differences. The astroglial scar border was well defined by 2 weeks postinjury in all transplanted rats, but the orientation and arrangement of astrocytic processes varied by transplant group (Fig. $7 A-D$ ). In FB-treated rats, astrocytic processes appeared disorganized and failed to exclude invading peripheral cells as evident by more diffuse globoid Iba-1-positive cells within the GFAP-positive scar border (Fig. $7 A, C$ ). In contrast, astrocyte processes formed a distinctive barrier that encircled and sequestered globoid Iba-1-positive immune cells in OEC-treated spinal cords (Fig. $7 B, D$ ). Hoechst nuclear staining also demonstrates that the astrocytic border formation was disrupted in FB- compared with OEC-treated rats (Fig. $7 A-D$, individual channel images).

To quantitatively assess if immune cell infiltration varied by cell transplantation type, we analyzed the differences in mean Iba- 1 and GFAP luminance in the stumps relative to the lesion core. FB-treated spinal cords 2 weeks postinjury had a greater difference in mean Iba-1 luminance than OEC-treated spinal cords, a finding consistent with higher levels of immune cell infiltration into the stumps of FB-treated rats (Fig. 7E; FB $1.9 \pm 0.5$ vs OEC $0.5 \pm 0.3, p=0.0031$ ). To control for the Iba- 1 luminance, differences in mean GFAP luminance were measured and again showed that FB- and OEC-treated rats did not differ (Fig. $7 F$ ). Our findings highlight the relationship between scar border formation and immune cell infiltration. We show that OECs integrate well with the astroglial scar and reduce immune cell activation and infiltration compared with FBs.

\section{Immunosuppression using cyclosporine-A enhances graft cell survival}

We show that OECs modulate the host immune response at 2 but not 8 weeks postinjury and suspect that this loss at 8 weeks is due to immune-mediated rejection of the transplanted cells. To determine whether immunosuppression would enhance OEC survival, CSA was administered to the rats before and throughout the study. CSA treatment enhanced the survival of both FBs and OECs at 2 and 8 weeks (Table 1). More transplanted cells in CSA-treated rats were found in the lesion core at 2 weeks compared with our findings of non-immunosuppressed rats (compare Figs. $8 A, B, 1 C, D$ ). At 2 weeks, FBs and OECs in CSA-treated (FB + CSA; OEC + CSA) rats migrated into the lesion core (Fig. $8 E$; FB $84 \pm 10 \%$, OEC $75 \pm 4 \%$ ). The CSA treatment significantly increased the percentage of the lesion volume filled by FBs $(29 \pm 12 \%)$ and OECs $(41 \pm 8 \%)$ compared with non-CSA-treated rats at 2 weeks (FB $3 \pm 3 \%, p=0.0131$; OECs $1 \pm 0.1 \%, p=0.0007)$. By 8 weeks postinjury CSA-treated rats still had both cell types surviving in the lesion core (Table 1; Fig. $8 C, D, E ; \mathrm{FB} 48 \pm 27 \%$, OEC $14 \pm 8 \%, p=0.0241$ ), and both formed bridges between the rostral and caudal stumps (Fig. $8 C, D$ ) compared with the non-CSA-treated rats at 8 weeks. CSA treatment preserved a limited percentage of transplanted cells in the lesion core (FB $8 \pm$ $9 \%$; OEC $4 \pm 3 \%$ ).
To evaluate if enhanced cell survival was due to suppression of the innate immune response after CSA administration, we measured Iba- 1 luminance levels as in Figure $6 \mathrm{~A}$. CSA reduced Iba-1 levels in both transplant groups at 2 and 8 weeks postinjury, with a greater reduction in FB- than OEC-treated rats. We also assessed immune cell infiltration by reporting the difference in mean Iba-1 luminance in the stumps and lesion core of transplanted rats. In both cell transplants, immune cell infiltration was markedly reduced after CSA treatment at 2 compared to 8 weeks (Fig. 8F; 2 week FB + CSA $0.6 \pm 0.1$ vs OEC + CSA $-0.2 \pm 0.1$; 8 week FB + CSA $0.6 \pm 0.4$ vs OEC + CSA $0.2 \pm 0.1)$. Interestingly, CSA treatment reduced Iba-1 luminance levels of FB- but not OEC-treated rats compared with their non-CSA controls (Fig. 8F; FB $1.9 \pm 0.5$ vs FB + CSA $0.6 \pm 0.1, p=0.0121$ ). These results suggest that CSA administration reduced the innate immune response after spinal cord transection and prolonged the survival of both FBs and OECs at the 2-week time point.

\section{Enhanced-OEC survival promotes preservation of neurons and axons}

To determine whether CSA-enhanced OEC survival promotes a beneficial response, we again assessed neuronal preservation. At 2 weeks neurons were found close to the astroglial scar border after CSA treatment (Fig. 9A). The neuron-free distance and the total distance between rostral and caudal stump neurons were comparable in the FB and OEC groups after CSA administration at both 2 and 8 weeks (CSA data not shown). Although the extent of tissue preservation in the stumps did not differ with CSAenhanced OEC survival, neurons now survived in the GFAPnegative lesion core of OEC + CSA-treated rats at 2 compared to 4 weeks in non-CSA-treated rats (compare Figs. 9B, 2B).

Next we asked if axons were preserved in the lesion core now that OECs survived to 8 weeks after injury and CSA treatment. Bundles of OECs ensheathed neurofilament-labeled axons that extend beyond the scar border, as reported in our 4-week observation (Fig. $3 F$ ). Remarkably, axons were found directly associated with OECs in the lesion core at 8 weeks (Fig. 9C). Confocal $3 \mathrm{D}$ visualization shows OECs completely surrounding axons in both horizontal (Fig. 9C, white arrows) and cross-sectional (Fig. $9 C$, white arrowhead) orientation. It is likely, therefore, that OECs not only provide a bridge for axons to grow into the lesion core, but also may play some functionally supportive role within the lesion core.

\section{OEC + CSA treatment enhances 5-HT axon protection from dieback}

To assess whether enhanced FB or OEC survival due to CSA treatment could preserve axons and promote axon regeneration, we identified raphespinal tract axons and analyzed: (1) the number of axons that crossed the border, (2) the area in the lesion core that contains 5-HT axons, and (3) the distance from the rostral border to the furthest extending 5-HT axon (Fig. 9D-F). Relative to non-immunosuppressed rats, CSA treatment enhanced the number of 5-HT axons that crossed the rostral astrocyte scar border in FB- and OEC-treated rats at 2 weeks (Fig. 9D; FB + CSA $34 \pm 21, p=0.0314$; OEC + CSA $86 \pm 9$ axons, $p=0.0023)$. At 8 weeks, CSA + OEC treatment produced a twofold greater number of 5-HT axons that crossed the border compared with OEC-treatment alone (Fig. 9D; OEC + CSA $46 \pm 18, p=$ 0.0487). We found larger areas of 5-HT-positive axons in the lesion core of CSA than non-CSA-treated rats in both transplant groups at 2 weeks (Fig. 9E; FB + CSA 19,718 $\pm 5707 \mu \mathrm{m}^{2}, p=$ 0.0020 ; OEC + CSA 33,013 $\left.\pm 8295 \mu \mathrm{m}^{2}, p=0.0018\right)$. Surpris- 
FB

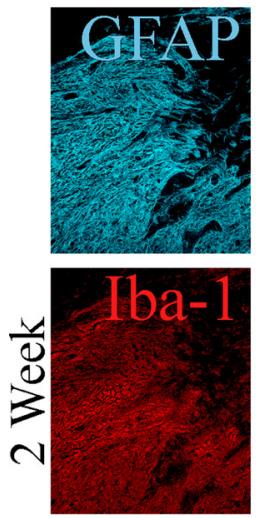

Toechst
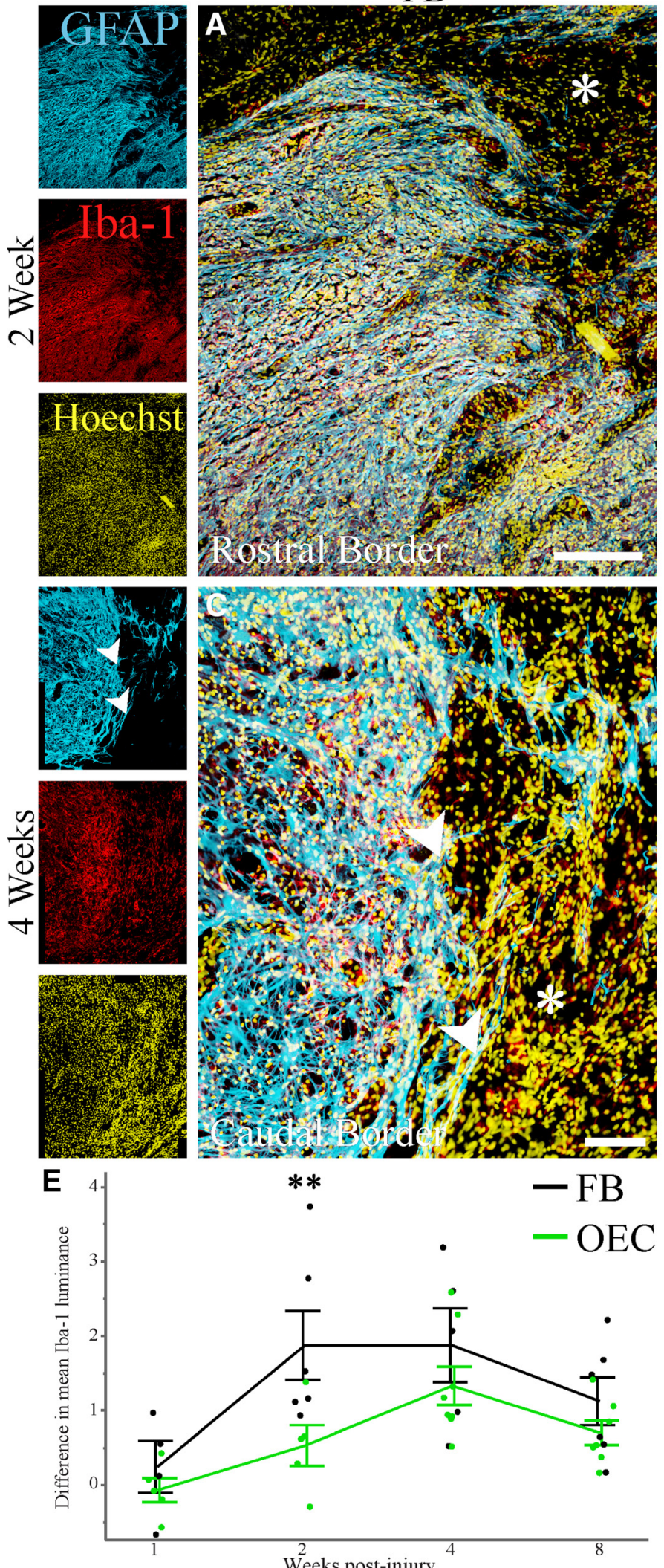

3
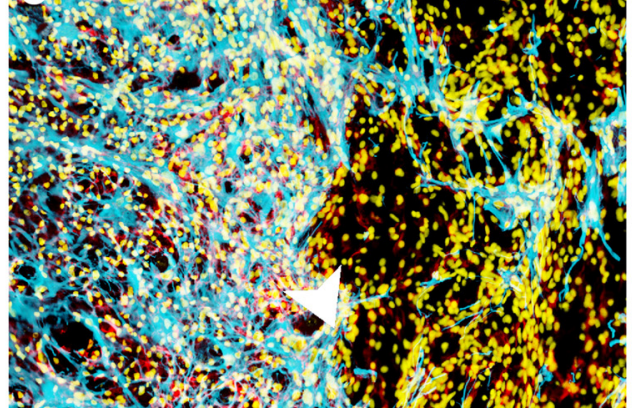

Now
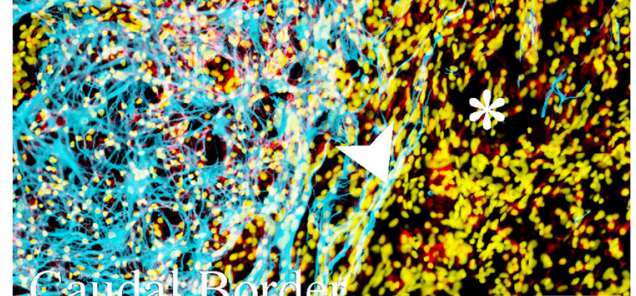

Weeks post-injury
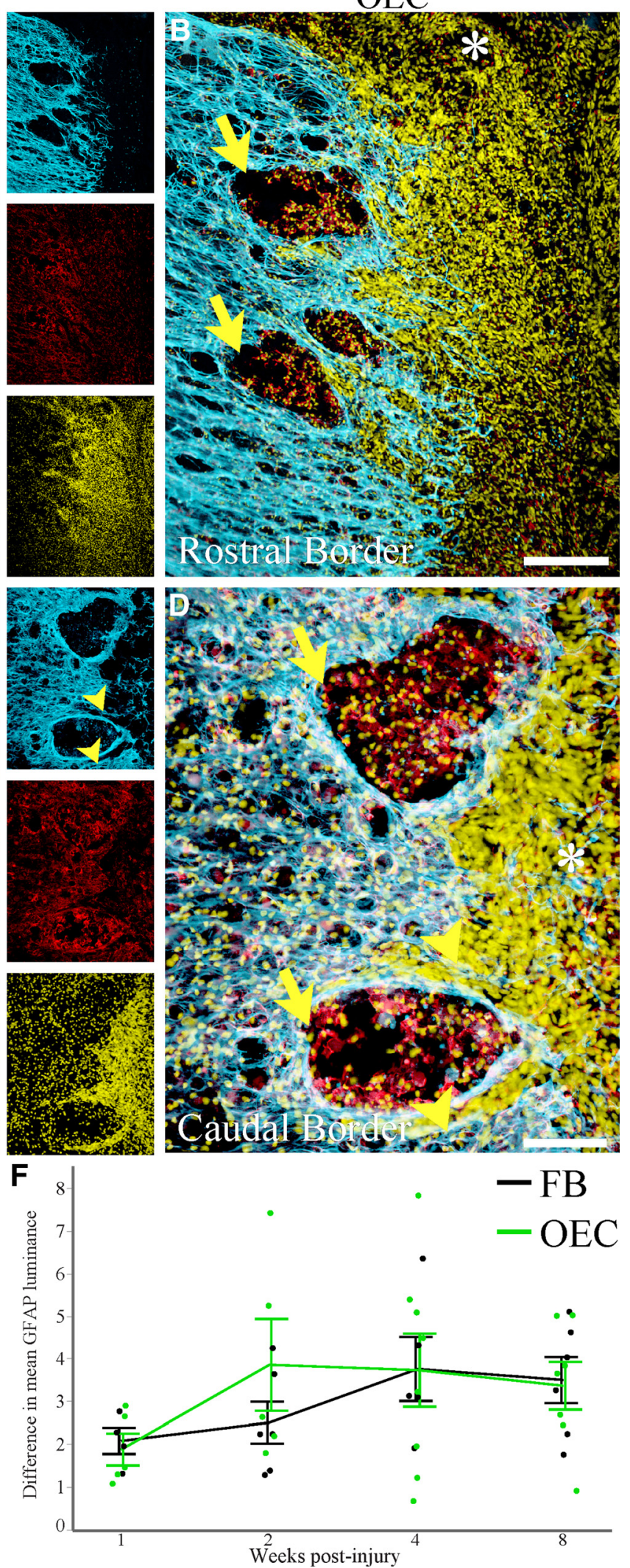

Figure 7. OECs reduce immune cell infiltration into the spinal cord stumps. $\boldsymbol{A}-\boldsymbol{D}$, Within the rostral $(\boldsymbol{A}, \boldsymbol{B})$ and caudal border $(\boldsymbol{C}, \boldsymbol{D})$ zones, astrocytes (GFAP, cyan) and activated macrophages/ microglia (Iba-1, red) are immunolabeled and nuclei are stained (Hoechst, yellow). These images from FB- $(\boldsymbol{A}, \boldsymbol{C})$ and OEC-treated $(\boldsymbol{B}, \boldsymbol{D})$ lesion sites are $2(\boldsymbol{A}, \boldsymbol{B})$ and 4 weeks $(\boldsymbol{C}, \boldsymbol{D})$ postinjury. Individual channels of the entire image are displayed on the left. The GFAP scar border (cyan image) is clearly defined $(\boldsymbol{A}-\boldsymbol{D})$. The distribution of Iba-1-positive immune cells (red image) between the GFAP-positive scar border and the lesion core $\left(^{*}\right)$ differs in the $\mathrm{FB}(\boldsymbol{A}, \boldsymbol{C})$ versus $\mathrm{OEC}(\boldsymbol{B}, \boldsymbol{D})$ sections. Spherical Iba- 1 immune cells are clustered and contained within distinct zones (yellow arrows) surrounded by astrocyte processes in OEC $-(\boldsymbol{B}, \boldsymbol{D})$ but not FB-treated rats $(\boldsymbol{A}, \boldsymbol{C})$. Astrocyte processes in FB-treated rats bundle together tightly and are oriented parallel (white arrowheads) to the scar border whereas they are organized more perpendicularly (yellow arrowheads) in OEC-treated rats. Hoechst nuclear staining (yellow image) shows an even (Figure legend continues.) 

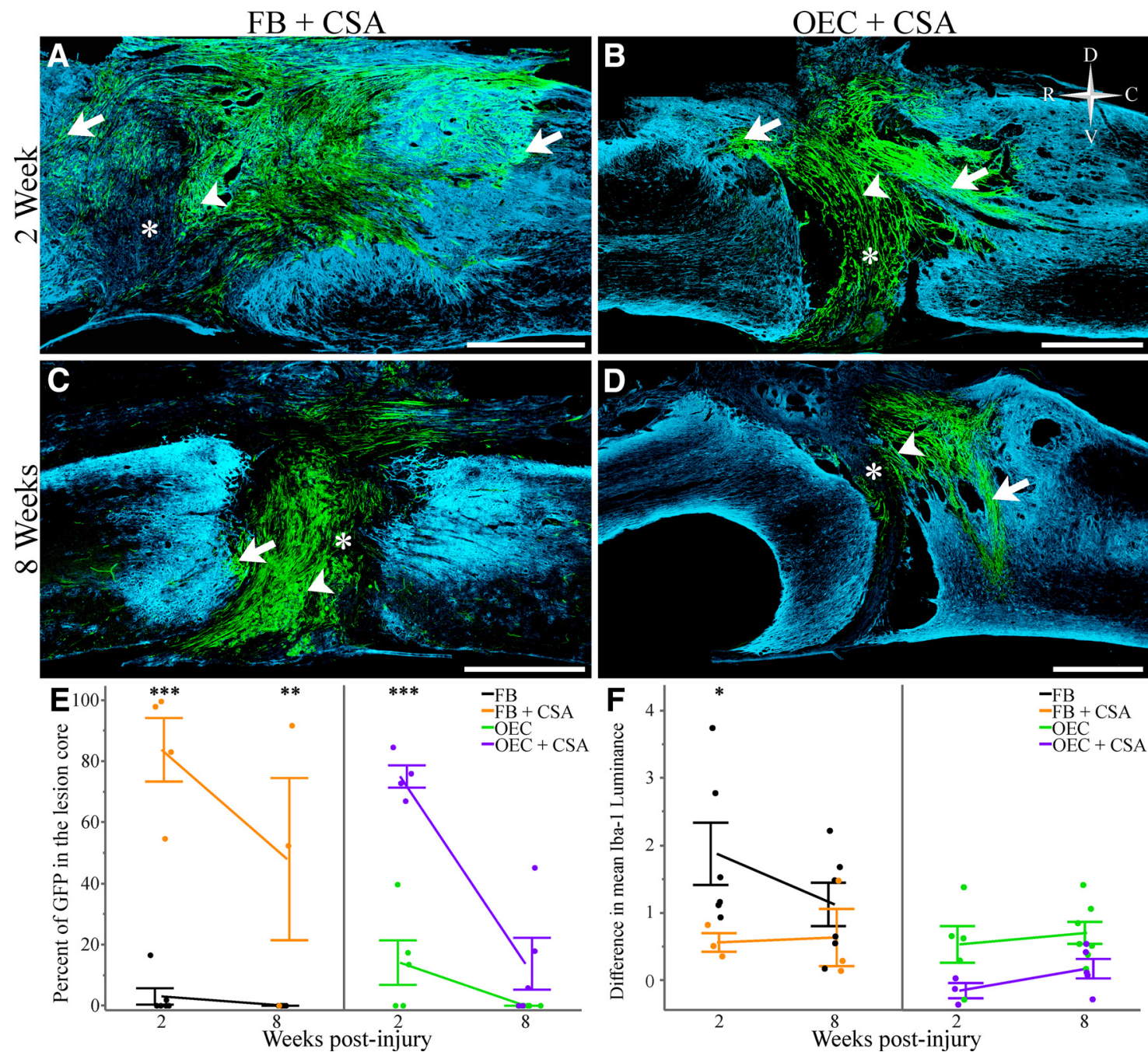

Figure 8. CSA administration improves graft survival at 2 and 8 weeks postinjury. $\boldsymbol{A}-\boldsymbol{D}$, With $C S A$ immunosuppression both $F B(\boldsymbol{A}, \boldsymbol{C})$ and $0 \mathrm{EC}(\boldsymbol{B}, \boldsymbol{D})$ transplanted cells survived and migrated into the lesion core $\left(^{*}\right)$ at 2 weeks $(\boldsymbol{A}, \boldsymbol{B})$ and were maintained at 8 weeks $(\boldsymbol{C}, \boldsymbol{D})$ postinjury. GFP-labeled cells were found in the stumps (white arrows) and lesion core (white arrowheads) in both FB- and OEC-treated rats. $E$, Comparison of the percentage of GFP in the lesion core of FB- (left, black) and OEC- (right, green) treated rats without or with CSA (FB + CSA, orange; OEC + CSA, purple). The volume of $F B s$ and $0 E C$ in the lesion core was larger with than without $C S A$ administration. $F$, The difference in Iba-1 luminance in the stumps relative to the lesion core demonstrates that immune cell infiltration was lower in 2 week CSA + FB- than in non-CSA FB-treated rats. The group means of lba--l luminance in OEC-treated rats did not differ with CSA treatment. Scale bars: $\boldsymbol{A}-\boldsymbol{D}, 1 \mathrm{~mm}$.

ingly, the distance of the furthest extending 5-HT axon increased in the FB- but not OEC-treated rats at 2 weeks with CSA administration (Fig. $9 F ; \mathrm{FB}-371 \pm 161$ vs FB + CSA $146 \pm 84 \mu \mathrm{m}, p=$ 0.0018). Yet at 8 weeks, 5-HT-positive axons were found further in the lesion core of OEC + CSA than FB + CSA-treated rats (Fig. $9 F ; \mathrm{FB}+\mathrm{CSA}-117 \pm 166$ vs OEC + CSA $361 \pm 137 \mu \mathrm{m}, p=$ 0.0089). Thus, CSA treatment promoted 5-HT axon preservation in FB-treated rats only at 2 weeks postinjury. Combined, these results indicate that OEC transplantation promotes the extension of 5-HT axons beyond the scar border and that CSA-enhanced survival of OECs preserves these axons in the lesion core longer.

\section{$\leftarrow$}

(Figure legend continued.) distribution of invading cells within the lesion site and stump of $\mathrm{FB}$-treated $(A, C)$ compared with the concentrated invading cells in the lesion site of $0 \mathrm{EC}-$ treated $(\boldsymbol{B}, \boldsymbol{D})$ rats. $\boldsymbol{E}, \boldsymbol{F}$, The difference in mean Iba- $1(\boldsymbol{E})$ and $\mathrm{GFAP}(\boldsymbol{F})$ luminance in the rostral and caudal stumps (Fig. $6 \mathrm{~A}$ ) relative to the lesion core. At 2 weeks, more lba-1-positive cells infiltrated the stumps of FB- than OEC-treated spinal cords. GFAP luminance served as a control and did not differ between FB- and OEC-treated spinal cords $(\boldsymbol{F})$. Scale bars: $\boldsymbol{A}, \boldsymbol{B}$, $200 \mu \mathrm{m} ; \boldsymbol{C}, \mathbf{D}, 100 \mu \mathrm{m}$.
Enhanced-OEC and FB survival reduces inhibitory factors at the injury site

To determine if CSA-enhanced OEC survival can reduce inhibitory factors in the lesion site beyond that observed with non-CSA-treated rats, we assessed CSPG luminance levels in the lesion core and the rostral and caudal stumps. We observed a time-dependent CSA treatment effect on the levels of CSPG luminance in the lesion core when transplant groups were combined ( 2 week CSA $2.7 \pm 0.3$ vs no CSA $2.3 \pm 0.2, p=0.0444 ; 8$ week CSA $1.9 \pm 0.2$ vs no CSA $2.7 \pm$ $0.5, p=0.0156)$, but not in the stumps. In the lesion core, CSPG levels remained higher in FB + CSA compared with OEC + CSA groups at 2 and 8 weeks (Fig. $9 H ; 2$ weeks, $p=0.0008 ; 8$ weeks, $p=$ 0.0438). At 2 weeks, however, spinal rats treated with OEC + CSA had higher CSPG levels in the lesion core than those treated with OECs alone (Fig. 9H; OEC $1.2 \pm 0.1$ vs OEC + CSA $2.1 \pm 0.3, p=$ 0.0144). CSPG levels in the lesion core were lower in FB + CSAcompared with FB-treated rats at 8 weeks (Fig. $9 H ; \mathrm{FB} 3.9 \pm 0.5$ vs $\mathrm{FB}+\mathrm{CSA} 2.4 \pm 0.1, p=0.0059)$. CSPG levels in the stump borders also were higher in FB + CSA groups compared with OEC + CSA groups at both time points (Fig. 9I; 2 weeks, $p=0.0326$; 8 weeks, $p=$ 

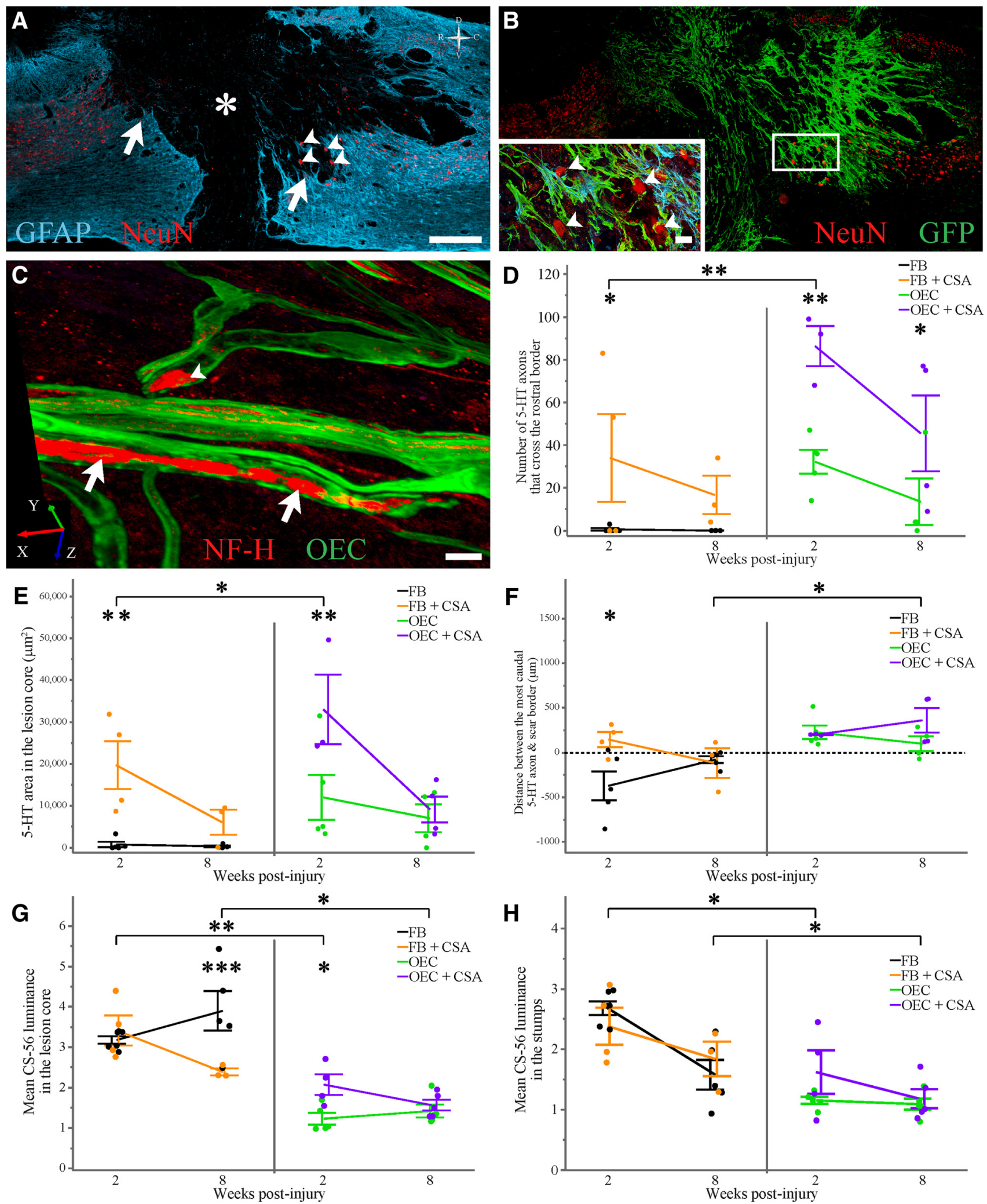

Figure 9. OEC survival in CSA-treated rats reduces neuronal degeneration and enhances serotonergic axonal preservation. $A, B$, The same section is illustrated in $\boldsymbol{A}$ (red neurons and cyan GFAP scar border) and $\boldsymbol{B}$ (red neurons and green $0 \mathrm{E} C \mathrm{~S}$ ). With combined (SA and $0 \mathrm{EC}$ treatment, neurons (white arrows) are detected close to the astrocyte scar border (cyan) at 2 weeks postinjury $(\boldsymbol{A})$. Neurons marked with white arrowheads $(\boldsymbol{A}, \boldsymbol{B})$ survived in the lesion core $\left(^{*}\right)$ and are surrounded by $\mathrm{OECS}(\boldsymbol{B}$, inset). $\boldsymbol{C}$, Confocal $3 \mathrm{D}$ visualization of neurofilament-labeled axons (red) within the lesion core completely encircled by $0 \mathrm{EC}$ in horizontal (white arrows) and cross-sectional (white arrowhead) orientation at 8 weeks postinjury in an OEC + CSA-treated rat. D, E, Compared to non-CSA-treated rats, the number of 5 -HT axons crossing the scar border was greater and the area of $5-\mathrm{HT}$ in the lesion core increased in $\mathrm{FB}+\mathrm{CSA}$ - and $\mathrm{OEC}+\mathrm{CSA}$-treated rats at 2 weeks. $\boldsymbol{F}$, The average distance between the furthest extending 5-HT axon and the scar border was greater in 8-week $0 \mathrm{EC}+\mathrm{CSA}$-treated rats than any other treatment group ( $\mathrm{FB}, \mathrm{FB}+\mathrm{CSA}, \mathrm{OEC}) . \mathbf{G}, \boldsymbol{H}$, The mean luminance of CSPGs was greater in the lesion core $(\boldsymbol{G})$ and stumps $(\boldsymbol{H})$ of $\mathrm{FB}+\mathrm{CSA}$ (orange) than in $0 \mathrm{EC}+\mathrm{CSA}$ (purple)-treated spinal cords at 2 and 8 weeks postinjury. Within the lesion core (G), FB-treated rats had reduced levels of CSPGs with versus without CSA administration at 8 weeks, whereas $0 \mathrm{EC}$-treated rats had lower levels of CSPGs than $0 \mathrm{EC}+$ CSA-treated rats at 2 weeks postinjury. Scale bars: $A, B, 500 \mu \mathrm{m} ;$ inset, $50 \mu \mathrm{m} ; \boldsymbol{C}, 5 \mu \mathrm{m}$. 

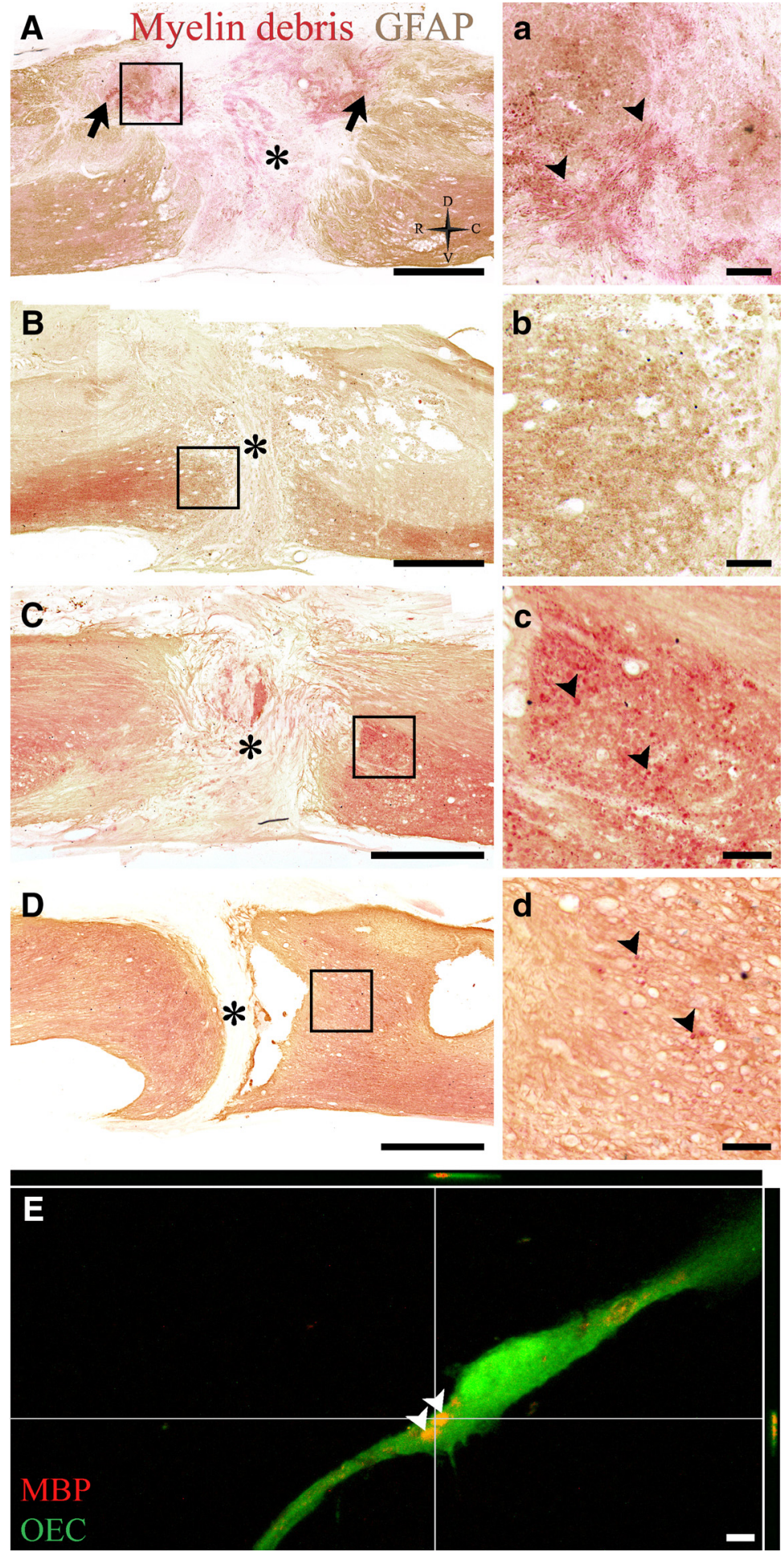

Figure 10. CSA treatment enhances $\mathrm{OEC}-$ mediated myelin uptake at 2 and 8 weeks postinjury. More 0il Red 0 -labeled myelin debris (red spheres) was located in the lesion core ${ }^{*}$ ) and stumps (brown, GFAP) of FB + CSA (A, C) than OEC + CSA-treated spinal cords $(\boldsymbol{B}, \boldsymbol{D}) . \boldsymbol{A}, \boldsymbol{B}$, Myelin debris (black arrows) was present both in the stumps and lesion core of $F B+C S A$, but not in OEC + CSA-treated spinal cords at 2 weeks postinjury. $C, D$, At 8 weeks postinjury, rats treated with $F B+C S A$ had more myelin debris present in the stumps than those treated with OEC + CSA. $\boldsymbol{a}-\boldsymbol{d}$, Enlarged images of the boxed areas (insets) in $\boldsymbol{A}-\boldsymbol{D}$ show more red punctate 0il Red 0-staining in FB + CSA than OEC + CSA-treated spinal cords. E, Orthogonal view of a Cell Tracker Green-labeled OEC (green) with engulfed MBP-positive myelin debris (red, white arrowheads) in vitro. Scale bars: $\boldsymbol{A}-\boldsymbol{D}, 1 \mathrm{~mm} ; \boldsymbol{a}-\boldsymbol{d}, 100 \mu \mathrm{m} ; \boldsymbol{E}, 5 \mu \mathrm{m}$.

0.0460). These findings imply that OECs reduce CSPG levels over time at the lesion site regardless of CSA treatment.

We qualitatively assessed levels of Oil Red $\mathrm{O}$ staining in $\mathrm{FB}+$ CSA- and OEC + CSA-treated injury sites to see whether immu- nosuppression altered the presence of myelin debris. Overall, a reduction in myelin debris was observed in CSA compared with non-CSA-treated spinal cords regardless of the cell transplant type (compare Figs. $10 A-D, 5 A, B, E, F)$. Punctate Oil Red O-stained debris was observed in 8 week FB- and OEC-treated spinal cords (Fig. 10c,d). Yet in FB-treated rats, myelin debris was found in the lesion core and extended well into the GFAP-positive stumps at 2 and 8 weeks (Fig. 10A,C). In contrast, OEC + CSA-treated rats contained minimal myelin debris in the lesion core and stumps (Fig. 10B,D). Due to the greater reduction of myelin debris in OEC- compared with FB-treated rats after immunosuppression, we asked if OECs could facilitate the clearance of myelin in vitro. To test whether OECs could engulf myelin particles, we added isolated myelin to cultured OECs. Confocal images revealed MBP-positive myelin fragments within the cytoplasm of OECs (Fig. 10E). This observation suggests that OEC phagocytic activity may be responsible for the removal of inhibitory myelin debris postinjury.

\section{Discussion}

Spinal cord injury produces a temporally regulated, pathological cascade of cellular changes that involve both central and peripheral cells which form a layered scar and create an inhibitory environment at the lesion site (Burda and Sofroniew, 2014; Cregg et al., 2014). The present study found that FBs and OECs differ in their modification of the lesion site after complete spinal cord transection. OECs, but not FBs, directly preserve neurons and 5-HT axons in the lesion core, reduce inhibitory CSPGs and myelin debris, and limit immune cell infiltration to reduce secondary tissue damage. When CSA was used to enhance OEC survival, the innate immune response and secondary tissue damage were reduced. The prolonged presence of OECs enhanced the survival of neurons and facilitated the regeneration of axons in the lesion site by contact-mediated mechanisms. Our results provide evidence that OECs are neuroprotective, mediate axon regeneration by providing a growth permissive substrate, and modify the inhospitable lesion site environment.

\section{OECs facilitate astroglial scar border formation}

After injury astrocytes form a protective barrier around the damaged CNS to limit further cell loss, restrict the spread of inflammation, and promote blood-brain barrier repair (Bush et al., 1999; Faulkner et al., 2004). We show that FBs, but not OECs, alter astrocyte barrier formation 
and that FB-transplanted rats have greater cell infiltration and overall tissue damage than rats transplanted with OECs. Reactive astrocyte processes in FB-treated rats were disorganized and failed to sequester immune cells, invading fibroblasts, or CSPG-positive cells within the spinal cord stumps. Thus, transplantation of skin FBs into the injured spinal cord intensifies the amount of cellular invasion by interfering with the astrocytic scar formation. In contrast to FBs, OECs intermingled with astrocytes and did not interfere with sequestration of invading peripheral cells. For example, immune cell infiltration peaked at 2 weeks in FB- but not until 4 weeks in OECtreated rats. Consistent with our findings, OECs can integrate and migrate with astrocytes in vivo, and do not cause astrocyte reactivity or an increase in CSPG levels following transplantation into intact spinal cords (Lakatos et al., 2000, 2003). Additionally, when OECs were added to an in vitro scar-like culture model they did not alter astrocytic reactivity and crossed the boundary zones that formed around meningeal fibroblasts (Khankan et al., 2015). Similarly, OECs extended along scar-forming astrocytes to bridge the lesion core following spinal cord injury. Thus OECs, compared with FBs, facilitate reactive astrocyte border formation and may contribute to the re-establishment of the glial limitans.

The STAT3-signaling pathway contributes to the organization of reactive astrocyte processes to limit invading cells (Herrmann et al., 2008). STAT3-null mice form a deficient astrocytic scar barrier after spinal cord injury that results in increased inflammation and neuronal loss (Herrmann et al., 2008; Wanner et al., 2013), and is reminiscent of our FB-treated spinal cords. Reactive astrocytes failed to isolate Iba-1-positive inflammatory cells and CSPG-positive meningeal fibroblasts in FB-, but not OECtreated rats. The cytokines that participate in the activation of the tripartite receptor complex involved in STAT3-signaling are CNTF, LIF, and IL-6 (Stahl and Yancopoulos, 1994) and are either expressed by OECs (Wewetzer et al., 2001; Asan et al., 2003; Herbert et al., 2012) or regulated by cytokine signaling after olfactory bulbectomy (Nan et al., 2001). The CNTF, LIF, and IL-6 receptors also may function in an OEC-mediated regulatory role of cytokine secretion (Nan et al., 2001; Wewetzer et al., 2001). Thus, OECs may interact synergistically with astrocytes to limit immune cell infiltration and secondary tissue damage via activation of the STAT3 pathway.

\section{OECs are immunomodulatory and neuroprotective}

Beck et al. (2010) used flow cytometry to quantitatively show that there is a time-dependent, multiphasic inflammatory response in which macrophages first peak at $7 \mathrm{~d}$ and then at $60 \mathrm{~d}$ after a spinal cord contusion. After complete spinal cord transection, the activation and peak of immune response was delayed in OEC- versus FB-treated rats. This delay in immune activation may have contributed to the prolonged survival of OECs compared with FBs. Thus, OECs appear to regulate inflammation at the injury site by reducing macrophage infiltration, limiting myelin debris, and preserving neurons close to the scar border. It is unclear how OECs support neurons in the lesion core, but a contact-mediated mechanism is likely, because these neurons are completed surrounded by OECs. This suggests that OECs can directly protect neurons independent of the astrocyte scar border.

CSA, a potent immunosuppressant that blocks T-cell activation and regulates other immune cells (Ho et al., 1996), reduced Iba-1 infiltration in FB- and OEC-treated rats to equivalent levels and prolonged FB and OEC survival in the lesion core. Yet neurons were found in the lesion core of OEC + CSA, but not FB + CSA-treated rats. This suggests that OECs preserve neurons by a different mechanism than CSA and corroborates an additive neu- roprotective effect with the combined use of OEC transplantation and CSA treatment. Presumably the OEC-mediated delay and attenuation of immune infiltration reduced secondary tissue damage, and when combined with the direct presence of OECs, protected neurons in the lesion core.

\section{OECs limit 5-HT axonal loss}

Our data support OEC-mediated immunomodulation and direct OEC-axon alignment as potential mechanisms that maintained 5-HT axons in the lesion core. Evans et al. (2014) found that infiltrating blood-derived macrophages are responsible for axonal dieback in a dorsal column crush model of spinal cord injury. Similarly, we observed more 5-HT axonal dieback in FBcompared with OEC-treated rats at the peak time of immune infiltration. CSA significantly increased 5-HT axonal preservation in FB-treated rats only at the 2 week time point by reducing the axonal dieback caused by immune infiltration. Conversely, no 5-HT axonal dieback was observed in OEC-treated rats with or without CSA treatment, suggesting that OECs in the lesion core facilitate 5-HT axon preservation via contact-mediated mechanisms, independent of CSA.

Previously we reported that alignment with OECs independently enhanced neurite outgrowth in an in vitro scar-like culture model of spinal cord injury (Khankan et al., 2015). Because OECs express multiple axon guidance and adhesion molecules, it is likely that these OEC-axonal interactions may both orient axons and enhance their growth postinjury. Both 5-HT and neurofilament-labeled axons aligned with palisading astrocytic processes and extended beyond the scar border when directly aligned with OECs. Interactions between transplanted OECs and scar-forming astrocytes seem to provide a surface that promotes axon regeneration, an arrangement described as the "pathway hypothesis" of neural repair ( $\mathrm{Li}$ et al., 2005b; Raisman and $\mathrm{Li}$, 2007). Beyond the scar border OECs intermingled in a trabecular network that formed OEC-lined conduits surrounded by a fibronectin-rich matrix, analogous to OECs after an olfactory nerve lesion (Li et al., 2005a), and within these conduits bundles of axons were ensheathed. Thus, OEC transplantation appears to provide structural scaffolds that facilitate axon regeneration by promoting astrocyte bridges and OEC-lined conduits.

OECs reduce inhibitory CSPGs and myelin debris postinjury A well known feature of the inhibitory glial scar is the upregulation and secretion of CSPGs by astrocytes and fibroblasts (McKeon et al., 1995; Morgenstern et al., 2002; Fitch and Silver, 2008). Several studies report that OECs reduce CSPG immunoreactivity in the injured spinal cord (Lakatos et al., 2003; Barbour et al., 2013), and our 8 week data show a direct correlation between the loss of OECs and the increase in CSPG density. In addition to reducing inhibitory CSPGs, OEC treatment reduced the buildup of myelin debris in the lesion core and spinal cord stumps. The accumulation of myelin debris inhibits axon regeneration (Filbin, 2003; Yiu and He, 2006) and stimulates secondary damage due to inflammation (Sun et al., 2010). Because OECs modulate the inflammatory response, this reduction in myelin debris may be due to the decrease in inflammation, however, OEC-treated rats still had lower levels of myelin debris after CSA administration. OECs are phagocytes that can engulf apoptotic olfactory receptor axons (Su et al., 2013; Nazareth et al., 2015). We now provide evidence that OECs can engulf myelin particles in vitro, reduce myelin debris in vivo after a complete spinal cord transection, and suggest that OECs likely contribute to clearing myelin debris. 
Astrocytes and microglia/macrophages respond to a traumatic injury by activating complex molecular signaling cascades, and the responses of multiple neural and peripheral cells generate both a chemical and mechanical barrier to axon regeneration. OECs can modify the astrocyte response by aligning astrocytic processes to provide pathways that would enhance axon outgrowth (Li et al., 2005b; current study). Despite the reduction in OEC survival, the number of 5-HT axons crossing the border still was increased and these axons were found further into the lesion core. Such findings suggest that engrafted OECs influenced the lesion microenvironment at an early time point postinjury, yet likely had long lasting effects on axon regeneration. Enhanced survival of OECs provided a bridge for regenerating axons to extend beyond the scar border and protected axons in the lesion core at later time points. Collectively, we suggest that OEC transplantation after a complete spinal cord transection mediates neuroprotective, immunomodulatory, and contact-associated mechanisms to create an environment that supports axonal regeneration.

\section{References}

Asan E, Langenhan T, Holtmann B, Bock H, Sendtner M, Carroll P (2003) Ciliary neurotrophic factor in the olfactory bulb of rats and mice. Neuroscience 120:99-112. CrossRef Medline

Barbour HR, Plant CD, Harvey AR, Plant GW (2013) Tissue sparing, behavioral recovery, supraspinal axonal sparing/regeneration following subacute glial transplantation in a model of spinal cord contusion. BMC Neurosci 14:106. CrossRef Medline

Beck KD, Nguyen HX, Galvan MD, Salazar DL, Woodruff TM, Anderson AJ (2010) Quantitative analysis of cellular inflammation after traumatic spinal cord injury: evidence for a multiphasic inflammatory response in the acute to chronic environment. Brain 133:433-447. CrossRef Medline

Burda JE, Sofroniew MV (2014) Reactive gliosis and the multicellular response to CNS damage and disease. Neuron 81:229-248. CrossRef Medline

Bush TG, Puvanachandra N, Horner CH, Polito A, Ostenfeld T, Svendsen CN, Mucke L, Johnson MH, Sofroniew MV (1999) Leukocyte infiltration, neuronal degeneration, and neurite outgrowth after ablation of scarforming, reactive astrocytes in adult transgenic mice. Neuron 23:297-308. CrossRef Medline

Buss A, Pech K, Kakulas BA, Martin D, Schoenen J, Noth J, Brook GA (2009) NG2 and phosphacan are present in the astroglial scar after human traumatic spinal cord injury. BMC Neurol 9:32. CrossRef Medline

Chandler CE, Parsons LM, Hosang M, Shooter EM (1984) A monoclonal antibody modulates the interaction of nerve growth factor with PC12 cells. J Biol Chem 259:6882-6889.

Colman DR, Kreibich G, Frey AB, Sabatini DD (1982) Synthesis and incorporation of myelin polypeptides into CNS myelin. J Cell Biol 95:598-608. CrossRef Medline

Cregg JM, DePaul MA, Filous AR, Lang BT, Tran A, Silver J (2014) Functional regeneration beyond the glial scar. Exp Neurol 253:197-207. CrossRef Medline

Evans TA, Barkauskas DS, Myers JT, Hare EG, You JQ, Ransohoff RM, Huang AY, Silver J (2014) High-resolution intravital imaging reveals that blood-derived macrophages but not resident microglia facilitate secondary axonal dieback in traumatic spinal cord injury. Exp Neurol 254:109120. CrossRef Medline

Faulkner JR, Herrmann JE, Woo MJ, Tansey KE, Doan NB, Sofroniew MV (2004) Reactive astrocytes protect tissue and preserve function after spinal cord injury. J Neurosci 24:2143-2155. CrossRef Medline

Filbin MT (2003) Myelin-associated inhibitors of axonal regeneration in the adult mammalian CNS. Nat Rev Neurosci 4:703-713. CrossRef Medline

Fitch MT, Silver J (2008) CNS injury, glial scars, and inflammation: inhibitory extracellular matrices and regeneration failure. Exp Neurol 209: 294-301. CrossRef Medline

Fitch MT, Doller C, Combs CK, Landreth GE, Silver J (1999) Cellular and molecular mechanisms of glial scarring and progressive cavitation: in vivo and in vitro analysis of inflammation-induced secondary injury after CNS trauma. J Neurosci 19:8182-8198. Medline
Granger N, Blamires H, Franklin RJ, Jeffery ND (2012) Autologous olfactory mucosal cell transplants in clinical spinal cord injury: a randomized double-blinded trial in a canine translational model. Brain 135:32273237. CrossRef Medline

Herbert RP, Harris J, Chong KP, Chapman J, West AK, Chuah MI (2012) Cytokines and olfactory bulb microglia in response to bacterial challenge in the compromised primary olfactory pathway. J Neuroinflammation 9:109-121. CrossRef Medline

Herrmann JE, Imura T, Song B, Qi J, Ao Y, Nguyen TK, Korsak RA, Takeda K, Akira S, Sofroniew MV (2008) STAT3 is a critical regulator of astrogliosis and scar formation after spinal cord injury. J Neurosci 28:7231-7243. CrossRef Medline

Ho S, Clipstone N, Timmermann L, Northrop J, Graef I, Fiorentino D, Nourse J, Crabtree GR (1996) The mechanism of action of cyclosporin A and FK506. Clin Immunol Immunopathol 80:S40-S45. CrossRef Medline

Hu R, Zhou J, Luo C, Lin J, Wang X, Li X, Bian X, Li Y, Wan Q, Yu Y, Feng H (2010) Glial scar and neuroregeneration: histological, functional, and magnetic resonance imaging analysis in chronic spinal cord injury. J Neurosurg Spine 13:169-180. CrossRef Medline

Khankan RR, Wanner IB, Phelps PE (2015) Olfactory ensheathing cell-neurite alignment enhances neurite outgrowth in scar-like cultures. Exp Neurol 269:93-101. CrossRef Medline

Kubasak MD, Jindrich DL, Zhong H, Takeoka A, McFarland KC, MuñozQuiles C, Roy RR, Edgerton VR, Ramón-Cueto A, Phelps PE (2008) OEG implantation and step training enhance hindlimb-stepping ability in adult spinal transected rats. Brain 131:264-276. CrossRef Medline

Lakatos A, Franklin RJ, Barnett SC (2000) Olfactory ensheathing cells and Schwann cells differ in their in vitro interactions with astrocytes. Glia 32:214-225. CrossRef Medline

Lakatos A, Barnett SC, Franklin RJ (2003) Olfactory ensheathing cells induce less host astrocyte response and chondroitin sulphate proteoglycan expression than Schwann cells following transplantation into adult CNS white matter. Exp Neurol 184:237-246. CrossRef Medline

Li Y, Field PM, Raisman G (2005a) Olfactory ensheathing cells and olfactory nerve fibroblasts maintain continuous open channels for regrowth of olfactory nerve fibres. Glia 52:245-251. CrossRef Medline

Li Y, Li D, Raisman G (2005b) Interaction of olfactory ensheathing cells with astrocytes may be the key to repair of tract injuries in the spinal cord: the "pathway hypothesis." J Neurocytol 34:343-351. CrossRef Medline

Lipson AC, Widenfalk J, Lindqvist E, Ebendal T, Olson L (2003) Neurotrophic properties of olfactory ensheathing glia. Exp Neurol 180: 167-171. CrossRef Medline

López-Vales R, Forés J, Navarro X, Verdú E (2006) Olfactory ensheathing glia graft in combination with FK506 administration promote repair after spinal cord injury. Neurobiol Dis 24:443-454. CrossRef Medline

Lu J, Féron F, Mackay-Sim A, Waite PM (2002) Olfactory ensheathing cells promote locomotor recovery after delayed transplantation into transected spinal cord. Brain 125:14-21. CrossRef Medline

Ma M, Wei T, Boring L, Charo IF, Ransohoff RM, Jakeman LB (2002) Monocyte recruitment and myelin removal are delayed following spinal cord injury in mice with CCR2 chemokine receptor deletion. J Neurosci Res 68:691-702. CrossRef Medline

McKeon RJ, Höke A, Silver J (1995) Injury-induced proteoglycans inhibit the potential for laminin-mediated axon growth on astrocytic scars. Exp Neurol 136:32-43. CrossRef Medline

Morgenstern DA, Asher RA, Fawcett JW (2002) Chondroitin sulphate proteoglycans in the CNS injury response. Prog Brain Res 137:313-332. CrossRef Medline

Nan B, Getchell ML, Partin JV, Getchell TV (2001) Leukemia inhibitory factor, interleukin-6, and their receptors are expressed transiently in the olfactory mucosa after target ablation. J Comp Neurol 435:60-77. CrossRef Medline

Nazareth L, Tello Velasquez J, Lineburg KE, Chehrehasa F, St John JA, Ekberg JA (2015) Differing phagocytic capacities of accessory and main olfactory ensheathing cells and the implication for olfactory glia transplantation therapies. Mol Cell Neurosci 65:92-101. CrossRef Medline

Perry AC, Wakayama T, Kishikawa H, Kasai T, Okabe M, Toyoda Y, Yanagimachi R (1999) Mammalian transgenesis by intracytoplasmic sperm injection. Science 284:1180-1183. CrossRef Medline

R Core Team (2015) R: a language and environment for statistical computing. Vienaa: R Foundation for Statistical Computing. 
Raisman G, Li Y (2007) Repair of neural pathways by olfactory ensheathing cells. Nat Rev Neurosci 8:312-319. CrossRef Medline

Ramón-Cueto A, Plant GW, Avila J, Bunge MB (1998) Long-distance axonal regeneration in the transected adult rat spinal cord is promoted by olfactory ensheathing glia transplants. J Neurosci 18:3803-3815. Medline

Ramón-Cueto A, Cordero MI, Santos-Benito FF, Avila J (2000) Functional recovery of paraplegic rats and motor axon regeneration in their spinal cords by olfactory ensheathing glia. Neuron 25:425-435. CrossRef Medline

Reier PJ, Houle JD (1988) The glial scar: its bearing on axonal elongation and transplantation approaches to CNS repair. Adv Neurol 47:87-138. Medline

Runyan SA, Phelps PE (2009) Mouse olfactory ensheathing glia enhance axon outgrowth on a myelin substrate in vitro. Exp Neurol 216:95-104. CrossRef Medline

Stahl N, Yancopoulos GD (1994) The tripartite CNTF receptor complex: activation and signaling involves components shared with other cytokines. J Neurobiol 25:1454-1466. CrossRef Medline

Su Z, Chen J, Qiu Y, Yuan Y, Zhu F, Zhu Y, Liu X, Pu Y, He C (2013) Olfactory ensheathing cells: the primary innate immunocytes in the olfactory pathway to engulf apoptotic olfactory nerve debris. Glia 61: 490-503. CrossRef Medline

Sun X, Wang X, Chen T, Li T, Cao K, Lu A, Chen Y, Sun D, Luo J, Fan J, Young W, Ren Y (2010) Myelin activates FAK/Akt/NF- $\kappa$ B pathways and provokes CR3-dependent inflammatory response in murine system. PLoS One 5:e9380. CrossRef Medline

Tabakow P, Raisman G, Fortuna W, Czyz M, Huber J, Li D, Szewczyk P, Okurowski S, Miedzybrodzki R, Czapiga B, Salomon B, Halon A, Li Y,
Lipiec J, Kulczyk A, Jarmundowicz W (2014) Functional regeneration of supraspinal connections in a patient with transected spinal cord following transplantation of bulbar olfactory ensheathing cells with peripheral nerve bridging. Cell Transplant 23:1631-1655. CrossRef Medline

Takashima A (2001) Establishment of fibroblast cultures. In: Current protocols in cell biology, pp 2.1.1-2.1.12. Hoboken, NJ: Wiley.

Takeoka A, Jindrich DL, Muñoz-Quiles C, Zhong H, van den Brand R, Pham DL, Ziegler MD, Ramón-Cueto A, Roy RR, Edgerton VR, Phelps PE (2011) Axon regeneration can facilitate or suppress hindlimb function after olfactory ensheathing glia transplantation. J Neurosci 31:4298-4310. CrossRef Medline

Wanner IB, Anderson MA, Song B, Levine J, Fernandez A, Gray-Thompson Z, Ao Y, Sofroniew MV (2013) Glial scar borders are formed by newly proliferated, elongated astrocytes that interact to corral inflammatory and fibrotic cells via STAT3-dependent mechanisms after spinal cord injury. J Neurosci 33:12870-12886. CrossRef Medline

Wewetzer K, Grothe C, Claus P (2001) In vitro expression and regulation of ciliary neurotrophic factor and its $\alpha$ receptor subunit in neonatal rat olfactory ensheathing cells. Neurosci Lett 306:165-168. CrossRef Medline

Yiu G, He Z (2006) Glial inhibition of CNS axon regeneration. Nat Rev Neurosci 7:617-627. CrossRef Medline

Zheng B, Ho C, Li S, Keirstead H, Steward O, Tessier-Lavigne M (2003) Lack of enhanced spinal regeneration in Nogo-deficient mice. Neuron 38:213-224. CrossRef Medline

Ziegler MD, Hsu D, Takeoka A, Zhong H, Ramón-Cueto A, Phelps PE, Roy RR, Edgerton VR (2011) Further evidence of olfactory ensheathing glia facilitating axonal regeneration after a complete spinal cord transection. Exp Neurol 229:109-119. CrossRef Medline 